\title{
Airborne Radar Observations of Severe Hailstorms: Implications for Future Spaceborne Radar
}

\author{
GERALD M. HEYMSFIELD \\ NASA Goddard Space Flight Center, Greenbelt, Maryland \\ LIN TIAN \\ NASA Goddard Space Flight Center, Greenbelt, and Morgan State University, Baltimore, Maryland \\ LiHUA Li AND MATTHEW MCLINDEN \\ NASA Goddard Space Flight Center, Greenbelt, Maryland \\ JAIME I. CERVANTES \\ NASA Goddard Space Flight Center, Greenbelt, and Science Systems and Applications, Inc., Lanham, Maryland
}

(Manuscript received 31 May 2012, in final form 20 March 2013)

\begin{abstract}
A new dual-frequency ( $\mathrm{Ku}$ and $\mathrm{Ka}$ band) nadir-pointing Doppler radar on the high-altitude NASA ER-2 aircraft, called the High-Altitude Imaging Wind and Rain Airborne Profiler (HIWRAP), has collected data over severe thunderstorms in Oklahoma and Kansas during the Midlatitude Continental Convective Clouds Experiment (MC3E). The overarching motivation for this study is to understand the behavior of the dualwavelength airborne radar measurements in a global variety of thunderstorms and how these may relate to future spaceborne-radar measurements. HIWRAP is operated at frequencies that are similar to those of the precipitation radar on the Tropical Rainfall Measuring Mission (Ku band) and the upcoming Global Precipitation Measurement mission satellite's dual-frequency ( $\mathrm{Ku}$ and $\mathrm{Ka}$ bands) precipitation radar. The aircraft measurements of strong hailstorms have been combined with ground-based polarimetric measurements to obtain a better understanding of the response of the $\mathrm{Ku}$ - and $\mathrm{Ka}$-band radar to the vertical distribution of the hydrometeors, including hail. Data from two flight lines on 24 May 2011 are presented. Doppler velocities were $\sim 39 \mathrm{~m} \mathrm{~s}^{-1}$ at $10.7-\mathrm{km}$ altitude from the first flight line early on 24 May, and the lower value of $\sim 25 \mathrm{~m} \mathrm{~s}^{-1}$ on a second flight line later in the day. Vertical motions estimated using a fall speed estimate for large graupel and hail suggested that the first storm had an updraft that possibly exceeded $60 \mathrm{~m} \mathrm{~s}^{-1}$ for the more intense part of the storm. This large updraft speed along with reports of 5-cm hail at the surface, reflectivities reaching $70 \mathrm{dBZ}$ at $\mathrm{S}$ band in the storm cores, and hail signals from polarimetric data provide a highly challenging situation for spaceborne-radar measurements in intense convective systems. The $\mathrm{Ku}-$ and $\mathrm{Ka}$-band reflectivities rarely exceed $\sim 47$ and $\sim 37 \mathrm{dBZ}$, respectively, in these storms.
\end{abstract}

\section{Introduction}

Currently flying spaceborne precipitation and cloud radars, including the Ku-band precipitation radar (PR) on the Tropical Rainfall Measuring Mission (TRMM) (Kummerow et al. 2000) and the W-band CloudSat (Stephens et al. 2008), provide global coverage of a

Corresponding author address: Gerald M. Heymsfield, Goddard Space Flight Center, Code 612, Greenbelt, MD 20771.

E-mail: gerald.heymsfield@nasa.gov variety of weather and cloud systems. With the success of these radars, the next spaceborne meteorologically oriented radars to be launched are the Global Precipitation Mission (GPM) dual-frequency ( $\mathrm{Ku}$ and $\mathrm{Ka}$ band) precipitation radar (DPR) in 2014 (Hou et al. 2008) and the W-band Doppler EarthCare Cloud Profiling Radar (Horie et al. 2010) in 2016. Because of spaceborne-antenna size constraints, the current and future radars all use relatively short wavelengths that pose challenges for observing deep convective storms with high rain rates or large ice particles including 
graupel and hail. As the hydrometeor sizes become comparable to or larger than the radar wavelength, Mie scattering occurs rather than Rayleigh scattering. As a consequence, the radar returns from typical groundbased S-band radars and those from shorter-wavelength satellite radars can be drastically different. TRMM and CloudSat missions have provided a wealth of information on intense deep convection, but we do not yet have comparable Ka-band measurements except through simulations (e.g., Tanelli et al. 2011).

Several studies have documented global characteristics of extremely intense deep convection (e.g., Zipser et al. 2006) by using radar profile characteristics with echo height (such as the $50-\mathrm{dBZ}$ contour) as a surrogate for updraft strength, which is not directly measured by TRMM. These analyses have provided the ability to quantify the intensity of convection globally and to understand a host of extremely important properties of the convection such as their regional and diurnal variations. It is also well known that when radio waves propagate through regions of high liquid water content or through regions with large liquid or ice hydrometeors they can be strongly attenuated. In CloudSat measurements of deep convection, large portions of high-reflectivity cores are often entirely missing because of severe W-band attenuation (e.g., Mitrescu et al. 2008). The strong attenuation in deep convection could also affect the TRMM PR at $\mathrm{Ku}$ band. It is often difficult to quantify hydrometeor characteristics in convection with single-frequency radars such as TRMM or CloudSat. Furthermore, it is difficult to know whether graupel or hail is present and the extent of Mie effects, attenuation, and even multiple scattering (e.g., Battaglia et al. 2006; Battaglia et al. 2010).

There are several downward-looking airborne radars that simulate spaceborne cloud and precipitation measurements in deep convection, hurricanes, and other weather phenomena. The only radar measurements to capture the full depth of deep convection have been with the single-frequency (X band) ER-2 Doppler Radar (EDOP) on a National Aeronautics and Space Administration (NASA) ER-2 aircraft (e.g., Heymsfield et al. 2010). The dual-frequency ( $\mathrm{Ku}$ and $\mathrm{Ka}$ band) Airborne Precipitation Radar (APR-2) on a medium-altitude $(<11 \mathrm{~km})$ DC-8 aircraft has provided measurements in hurricanes and occasional strong tropical oceanic convective cells (e.g., Sadowy et al. 2003; Durden et al. 2003), but it is limited primarily by considerations of aircraft safety when studying land-based deep convection.

The motivation for this paper is to understand the behavior of dual-frequency Ku-/Ka-band airborne radar measurements in deep convection through case study and how these measurements may relate to spaceborneradar measurements. One question that needs to be addressed for the upcoming GPM DPR is how well the $\mathrm{Ku}$-/Ka-band radar performs in strong midlatitude convection. The TRMM PR has observed severe convective events within $\pm 35^{\circ}$ latitude, such as in the southern portion of the U.S. southern Great Plains (SGP). There have been no dual-wavelength $\mathrm{Ku}-/ \mathrm{Ka}$ band airborne or spaceborne measurements from these more intense storms, however. The Ka-band wavelength on DPR is better in more moderate rain and snow since it suffers from attenuation in convection. In this paper, we will present the first dual-frequency $\mathrm{Ku}$ - and $\mathrm{Ka}$ band radar measurements over severe hailstorms from the High-Altitude Imaging Wind and Rain Airborne Profiler (HIWRAP). The measurements were taken near central Oklahoma during the Midlatitude Continental Convective Clouds Experiment (MC3E). We begin with a HIWRAP instrument description and data processing in section 2 , followed by an overview of the two severe hailstorms and their environmental conditions in section 3. Section 4 presents HIWRAP and ground-based polarimetric observations of these hailstorms that have significant scattering and attenuation at $\mathrm{Ku}$ and $\mathrm{Ka}$ bands. Section 5 presents interpretations from the observations and their implications for TRMM, GPM, and other future satellite missions. To be specific, the magnitudes of updrafts and the usefulness of the dualfrequency ratio (DFR) are examined. Since knowledge of hydrometeor size distributions is poor for the strong convective regions studied, simple single-hailstone calculations are presented to provide insight on DFR.

\section{HIWRAP instrument description and processing}

HIWRAP is a dual-frequency ( $\mathrm{Ku}$ and $\mathrm{Ka}$ band) and dual-beam conically scanning $\left(30^{\circ}\right.$ and $40^{\circ}$ incidence angles) Doppler radar system that was developed for remote operation on the NASA Global Hawk for studying winds in precipitation regions in hurricanes ( $\mathrm{Li}$ et al. 2011). It utilizes solid-state power amplifiers, versatile waveforms, and pulse compression to achieve simultaneous transmit and receive at different frequencies and different beam positions. It flew for the first time on the NASA Global Hawk during the Genesis and Rapid Intensification Processes field campaign in 2010 with a downward-looking conical scan antenna (Braun et al. 2013). HIWRAP has frequencies that are similar to those of GPM, and it flew during $\mathrm{MC} 3 \mathrm{E}$ with a new nonscanning (nadir pointing) antenna designed for the ER-2 (Table 1). ${ }^{1}$ For each radar

\footnotetext{
${ }^{1}$ The $33.7-\mathrm{GHz}$ frequency was used for MC3E rather than HIWRAP's upper band $(35.5 \mathrm{GHz})$, which is similar to the GPM frequency, because the ER-2 antenna had better voltage standing wave ratio performance at the lower sideband.
} 
TABLE 1. HIWRAP ER-2 system parameters during MC3E.

\begin{tabular}{|c|c|c|}
\hline \multirow[b]{2}{*}{ Parameters } & \multicolumn{2}{|c|}{ Specifications } \\
\hline & $\mathrm{Ku}$ band & Ka band \\
\hline \multirow[t]{2}{*}{ Frequency $(\mathrm{GHz})$} & Chirp mode: 13.915 & Chirp mode: 33.733 \\
\hline & Pulse mode: 13.904 & Pulse mode: 33.716 \\
\hline Transmitter peak power $(\mathrm{W})$ & 25 & 8 \\
\hline Antenna gain $(\mathrm{dB})$ & 34.8 & 42.0 \\
\hline Antenna 3-dB beamwidth (along track; ${ }^{\circ}$ ) & 3.07 & 1.23 \\
\hline Antenna 3 -dB beamwidth ( $\operatorname{cross}$ track; $\left.{ }^{\circ}\right)$ & 2.96 & 1.19 \\
\hline $\mathrm{PRF}(\mathrm{Hz})$ & $4516 / 3589$ & $4516 / 3589$ \\
\hline \multirow[t]{2}{*}{ Pulse width $(\mu s)$} & Chirp mode: 20 & Chirp mode: 20 \\
\hline & Pulse mode: 2 & Pulse mode: 2 \\
\hline Receiver bandwidth (MHz) & 2 & 2 \\
\hline Doppler range $\left(\mathrm{m} \mathrm{s}^{-1}\right)$ & \pm 97 & \pm 40 \\
\hline \multirow[t]{2}{*}{ Min detectable reflectivity ( $\mathrm{dB} Z$ ) (at $10 \mathrm{~km}$ and $0.5-\mathrm{s}$ avg) } & Chirp mode: -0.5 & Chirp mode: -10.6 \\
\hline & Pulse mode: 9.5 & Pulse mode: -2.9 \\
\hline
\end{tabular}

frequency ( $\mathrm{Ku}$ or $\mathrm{Ka}$ band), a pulse sequence of 2, 20, and $2 \mu \mathrm{s}$ was used for the data in this paper (McLinden et al. 2013). The first 2 - $\mu$ s short pulse is used to obtain returns near the surface since strong surface returns contaminate the near-surface rain signal through pulse compression range sidelobes in the chirp channel. The second short pulse is used to obtain returns near the radar in the "blind" zone of the 20- $\mu$ s chirp pulse. HIWRAP's beams are not matched as would be desired for dualfrequency algorithms since matched beams would decrease the Ka-band radar sensitivity significantly ( $~ 8 \mathrm{dBZ})$. Some of the effects from beam mismatch can be reduced through averaging the higher-resolution Kaband measurements along track, but such averaging was not performed here.

Calibration was performed by monitoring radar system stability with an internal calibration during flight and then by using the ocean-surface normalized radar cross section (NRCS) for external calibration (e.g., Tanelli et al. 2006). The radar system stability is monitored since it undergoes extreme temperature changes during the flight. This is accomplished using a calibration pulse obtained from an attenuated sample of the transmit pulse, which is passed through the digital receiver along with the received weather returns. An initial calibration was performed using this sampled calibration pulse along with the measured variables in the radar equation. This provides a continuous end-to-end system calibration during the flight. The final calibration was performed using the ocean surface as an external reference, similar to previous literature approaches. As mentioned in Tanelli et al. (2006) and earlier papers, the $\mathrm{Ku}$-band NRCS over ocean at $10^{\circ}$ incidence angle is $\sim 7.3 \mathrm{~dB}$ as based on TRMM satellite and airborne measurements. This value is also close to what is calculated from ocean-surface scatter models. On the basis of this well-accepted NRCS, we adjusted our internal calibration to about $1 \mathrm{dBZ}$ lower to match this value. The HIWRAP-derived NRCS was obtained using surface returns over the Gulf of Mexico, where the ER-2 performed roll maneuvers. For $\mathrm{Ka}$ band, we followed an approach similar to that of Tanelli et al. (2006) in which the $\mathrm{Ka}$ - and $\mathrm{Ku}$-band reflectivities are matched near cloud top where the scatterers are assumed to be Rayleigh scattering at both frequencies. We adjusted the Kaband reflectivity downward by $\sim 1.7 \mathrm{dBZ}$ to match the $\mathrm{Ku}$ band. This provides a consistent calibration approach that resolves any fluctuations in transmit power or receiver gain that occur during flight as a result of changes in temperature and altitude. The final calibration should have an accuracy of better than $1 \mathrm{~dB}$ at $\mathrm{Ku}$ and $\mathrm{Ka}$ bands relative to TRMM and APR-2 and, it is presumed, close to an absolute calibration.

The folding and accuracy of the Doppler velocities are of interest because the vertical motions in the subsequent data are very large. HIWRAP uses dual pulse repetition frequencies (PRF) to expand the Nyquist interval. For the 3589- and 4516-Hz PRFs used at both frequencies, the corresponding Doppler Nyquist velocities are 20 and $25 \mathrm{~m} \mathrm{~s}^{-1}$ at $\mathrm{Ku}$ band and are 9 and $12 \mathrm{~m} \mathrm{~s}^{-1}$ at Ka band (Table 1). With the staggered PRF approach used by HIWRAP, the effective Nyquist velocities are a larger by a factor of 4 than the single-PRF estimates above. These staggered PRF estimates were used to unfold the single-PRF Doppler velocity estimates since the latter have lower standard deviations (e.g., Doviak and Zrnić 1993, 171-175). This approach worked well for $\mathrm{Ku}$ - and Ka-band velocities. The accuracy of the Doppler velocities is discussed in the appendix as it relates to this paper. 


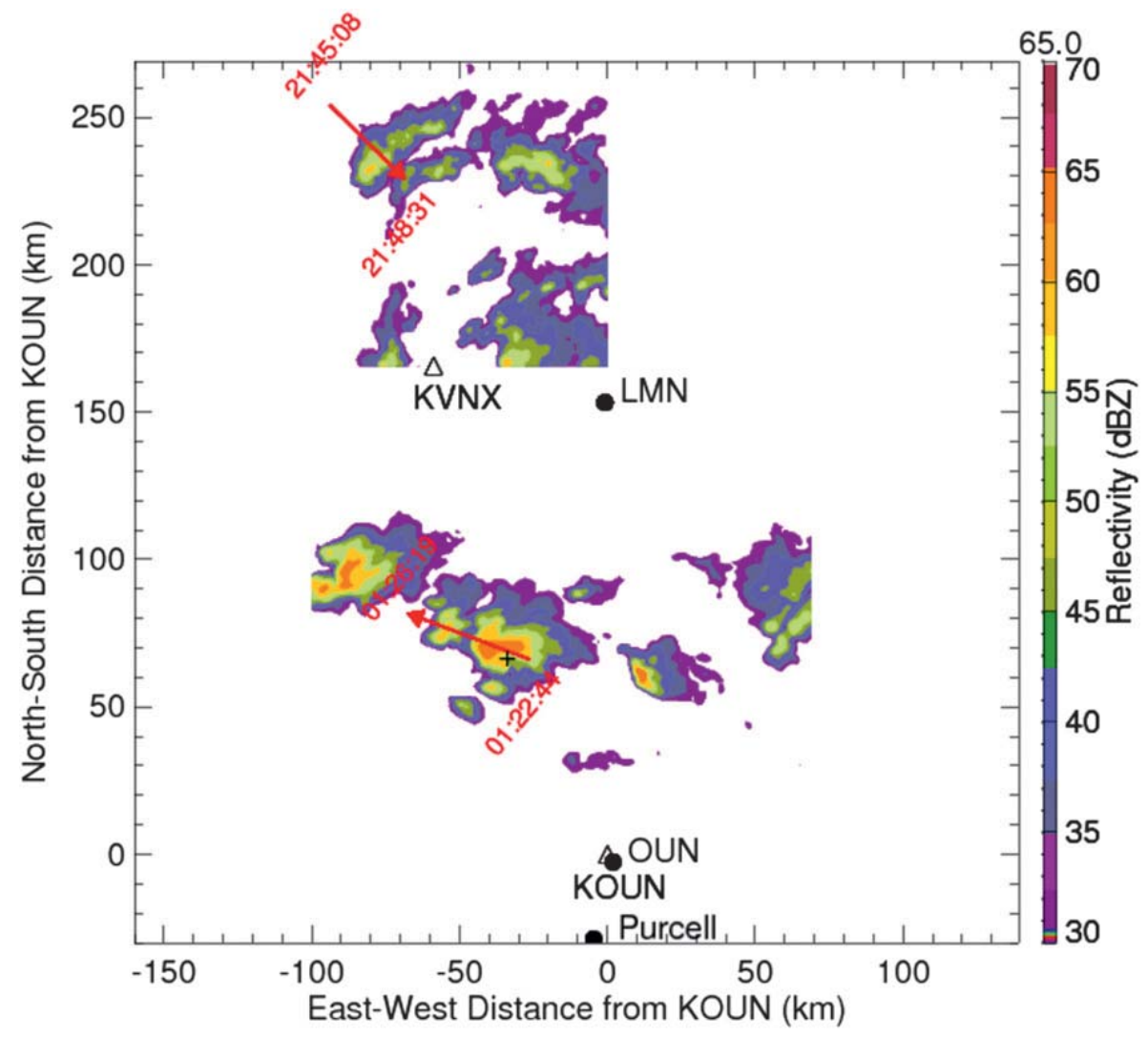

FIG. 1. Horizontal cross section of reflectivity at $3 \mathrm{~km}$ AGL from KOUN at 0121 UTC 24 May and KVNX at 2143 UTC 24 May. The red arrows are the ER-2 flight tracks during 0122-0126 and 2145-2148 UTC. The locations of the OUN and LMN soundings and the KOUN and KVNX radars are marked.

\section{Overview of the hailstorms}

Conditions were highly favorable for severe weather during 23-24 May 2011 in the Oklahoma-Kansas region. There were two ER-2 flights and several severe thunderstorm overpasses during this period; the first flight was from 2133 UTC 23 May to 0131 UTC 24 May, and the second flight was between 1920 and 2240 UTC on 24 May. In the following, we will give a general description of the environmental conditions and time evolution of the storm. Two cases of intense convective storms are presented in this paper. Case $1(\mathrm{C} 1)$ during the first flight was located northwest of the S-band polarimetric radar located at Norman, Oklahoma (KOUN). Case 2 (C2) during the second flight was located near the Kansas-Oklahoma border within range of the Weather Surveillance Radar-1988 Doppler (WSR-88D) S-band polarimetric radar located at Vance Air Force Base in Oklahoma (KVNX). Figure 1 shows the general locations of the two flight lines, S-band radars, soundings, and storms of interest superimposed on a 3-km AGL reflectivity map. All heights in this paper are above ground level, with the exception of upper-air sounding heights, which are above mean sea level.

\section{a. Upper-air soundings}

The upper-air soundings at Norman (OUN) and Lamont (LMN), Oklahoma, provide general environmental conditions for $\mathrm{C} 1$ and $\mathrm{C} 2$, respectively. The 0000 UTC OUN sounding (Fig. 2) was closest to $\mathrm{C} 1$ and showed a pseudoadiabatic convective available potential energy (CAPE) of $\sim 3600 \mathrm{~J} \mathrm{~kg}^{-1}$, but special soundings launched as part of MC3E at Purcell, Oklahoma, showed even larger instability, with CAPE of $3800-4200 \mathrm{~J} \mathrm{~kg}^{-1}$ between 1732 and 2030 UTC. The 1800 UTC LMN sounding (Fig. 3) was closest to $\mathrm{C} 2$ and showed a CAPE of $\sim 4400 \mathrm{~J} \mathrm{~kg}^{-1}$; the 2100 UTC LMN sounding had a slightly lower CAPE of $3600 \mathrm{~J} \mathrm{~kg}^{-1}$. The freezing level is at $\sim 4.3-\mathrm{km}$ altitude in both soundings. The extreme instability in these soundings provides a ballpark estimate of over $80 \mathrm{~m} \mathrm{~s}^{-1}$ using $w_{\max }=(2 \times \mathrm{CAPE})^{1 / 2}$, which indicates the maximum vertical motion at the equilibrium level calculated from the positive area in CAPE. The equilibrium level is $\sim 175 \mathrm{hPa}(\sim 13 \mathrm{~km}$ MSL) for the above soundings. The CAPE-derived updraft will never be realized because of precipitation loading and other factors, but it suggests the likelihood of very intense updrafts. The bulk Richardson number was $41 \mathrm{~m}^{2} \mathrm{~s}^{-2}$ at 


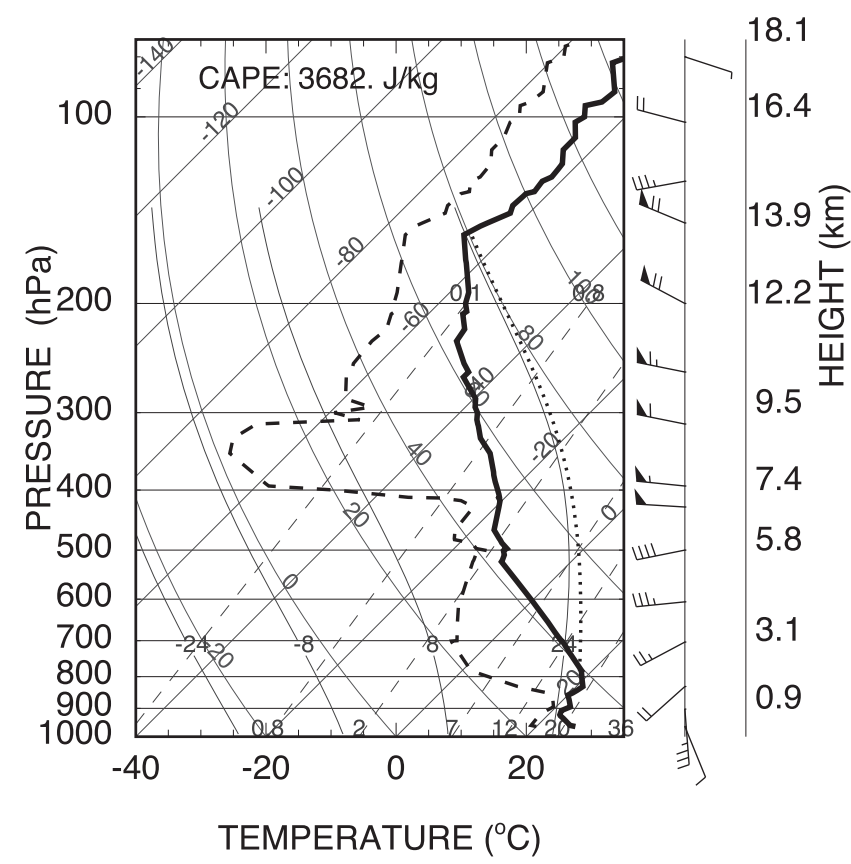

FIG. 2. Upper-air sounding for storm $\mathrm{C} 1$ from OUN at 0000 UTC 24 May 2011. The dotted line shows the lifted-parcel pseudoadiabat.

OUN (Fig. 2) and 107-213 $\mathrm{m}^{2} \mathrm{~s}^{-2}$ at the LMN soundings. These values are higher than typical supercell environments (e.g., Weisman and Klemp 1982).

\section{b. Storm C1}

During $\mathrm{C} 1$, an intense convective line developed to the northwest of KOUN with anvils trailing eastward. Figure 4 shows a time evolution of the peak reflectivity in the $\mathrm{C} 1$ flight line as derived from KOUN plan position indicator (PPI) reflectivity scans. The maximum KOUN reflectivities exceed $70 \mathrm{~dB} Z$ prior to the ER-2 pass, with values as large as $75 \mathrm{~dB} Z$ around $15-20 \mathrm{~min}$ prior to the pass. The $60-\mathrm{dB} Z$ echo extends up to $12-13 \mathrm{~km}$ throughout the storm's period, and the 55-dBZ contour extends up to $15-\mathrm{km}$ altitude $5-10 \mathrm{~min}$ prior to the ER-2 pass, suggesting a strengthening of the updraft.

The ER-2 made several passes over large cells during the evening of 23 May and into the early morning of 24 May. The maximum reflectivity observed by KOUN is $70 \mathrm{dBZ}$ for a cell located a few kilometers north of the flight line. By the time the ER-2 flew over $\mathrm{C} 1$ at 0121 UTC, the reflectivity decreased slightly but still exceeded $65 \mathrm{dBZ}$. Figure 5 shows that the differential reflectivity $Z_{\mathrm{DR}}$ at $3 \mathrm{~km}$ AGL within the high-reflectivity region was near or slightly below $0 \mathrm{~dB}$. Such a feature, called the $Z_{\mathrm{DR}}$ hail signature by Bringi et al. (1986) and Aydin et al. (1986), has been used to detect hail shafts penetrating below the melting level (Fig. 2). There also appears to be a " $Z_{\mathrm{DR}}$ ring" signature that is frequently

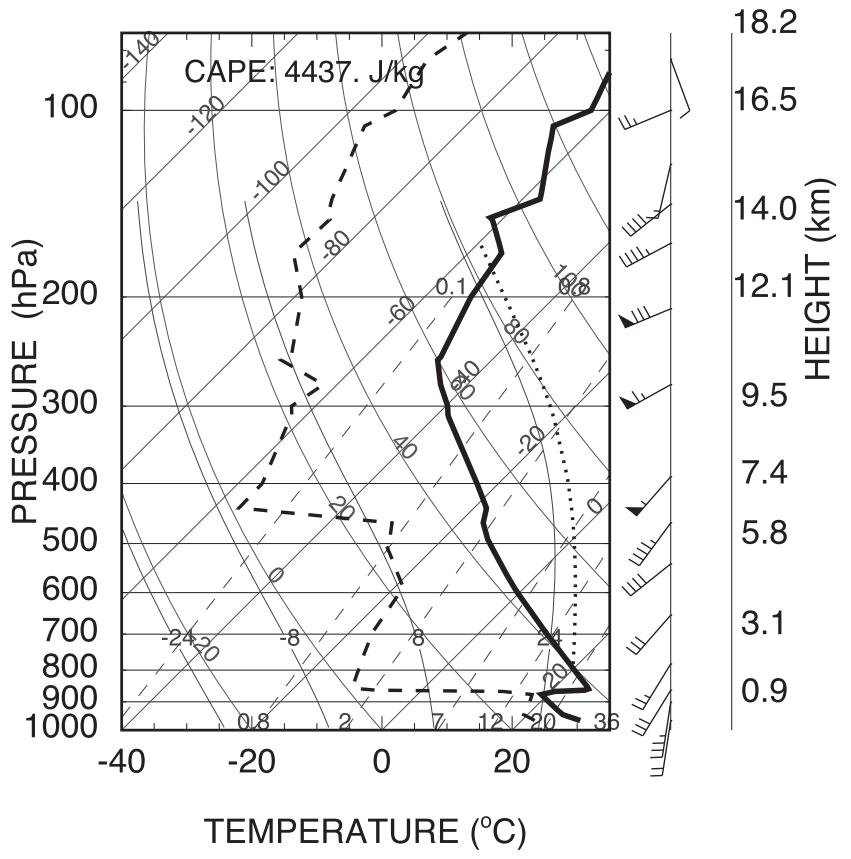

FIG. 3. As in Fig. 2, but from LMT at 2100 UTC 24 May 2011 for storm $\mathrm{C} 2$.

observed in supercells in midlevels (e.g., Kumjian and Ryzhkov 2008; Payne et al. 2010). The horizontal cross section at $7 \mathrm{~km}$ (Fig. 6a) shows a $Z_{\mathrm{DR}}$ column located about $1 \mathrm{~km}$ south of the flight line reaching up to $7 \mathrm{~km}$. This is accompanied by a reduction of cross-correlation coefficient $\rho_{h v}$ (Fig. 6b), which may be an indication of wet growth of large hail (diameter $>2.5 \mathrm{~cm}$ as defined by the U.S. National Weather Service) (Picca and Ryzhkov 2012). There were numerous hail reports in the National Oceanic and Atmospheric Administration Storm Prediction Center storm reports, including five within $15 \mathrm{~min}$ of the radar data shown in Fig. 5 with hail sizes between 2.54 and $5 \mathrm{~cm}$. The ER-2 flight lines over this storm are about $80 \mathrm{~km}$ away from the KOUN radar so that its beam resolution is about $1.3 \mathrm{~km}$ wide with a $250-\mathrm{m}$ gate spacing, which means that hail detection should not be a problem given the large size of the high-reflectivity core.

\section{c. Storm $C 2$}

Later in the day on 24 May, storms first fired up at about 1840 UTC along the dryline, and then they developed into a north-south-oriented line of supercells during the latter part of the second ER-2 flight. A possible weak tornado, hail reports, and strong winds were associated with this group of storms near the time of the C2 overpass. After 2200 UTC, there was at least one report of $4-5-\mathrm{cm}$ hail and several possible tornadoes with these same storms, as well as one report of $10-\mathrm{cm}$ hail in the vicinity of $\mathrm{C} 2$. At least 12 tornadoes developed with this line of supercells, mainly to the south. 


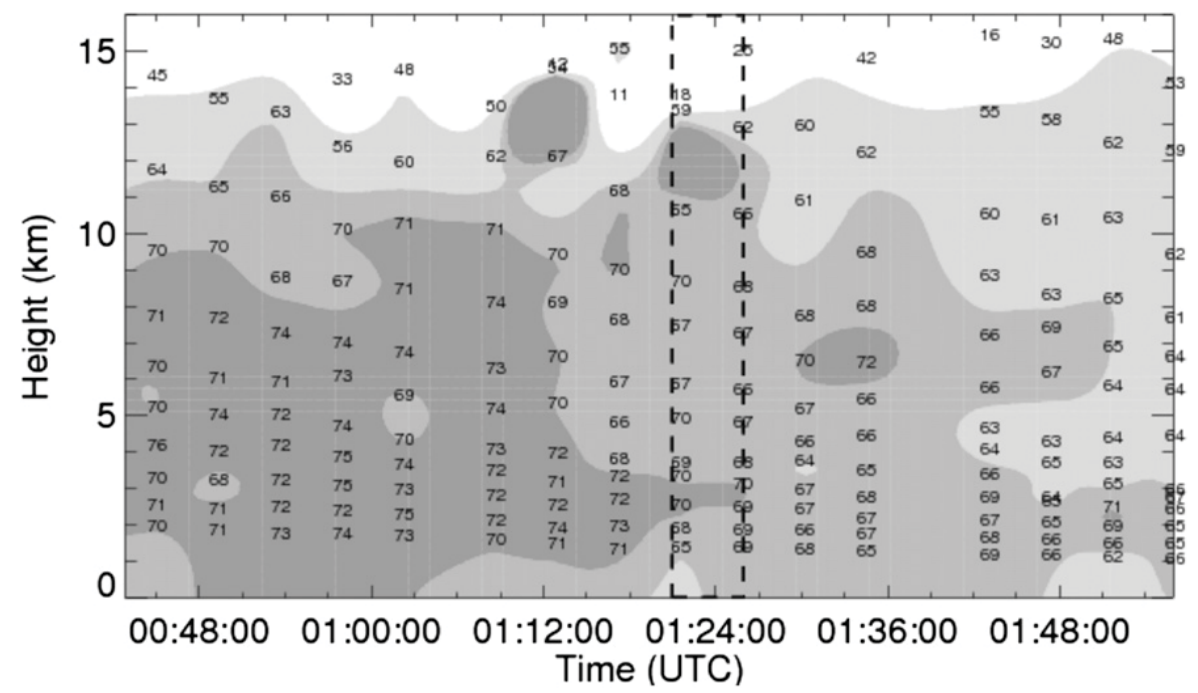

FIG. 4. Time history of maximum reflectivity for storm $\mathrm{C} 1$ overflown by ER-2 (Fig. 1). The vertical dashed lines bound the period of the ER-2 flight over the storm. Contour levels are for 50,65 , and $70 \mathrm{dBZ}$ (lighter to darker); calculated maximum values are also indicated (dBZ). The plot was derived from KOUN WSR-88D PPI scans.

Figure 7 reveals that reflectivity values were not as high as for $\mathrm{C} 1$. The reflectivity did not exceed $70 \mathrm{~dB} Z$ except at approximately 2200-2208 UTC at which time a $>70-\mathrm{dBZ}$ echo appears at $7-9-\mathrm{km}$ altitude and then descends toward the surface afterward. The $50-\mathrm{dB} Z$ contour extends up to about $11 \mathrm{~km}$ as compared with $13 \mathrm{~km}$ for $\mathrm{C} 1$. The ER-2 flew across an intense convective cell north of KVNX (Fig. 8). Unlike the previous case, we did not observe the $Z_{\mathrm{DR}}$ ring and hail signature near the surface. Although a positive $Z_{\mathrm{DR}}$ column reached up to $5 \mathrm{~km}$ AGL, we did not see an obvious reduction of $\rho_{h v}$ for this particular cell (not shown). In the following section, we present the observations from $\mathrm{C} 1$ and $\mathrm{C} 2$ to gain an understanding of both the vertical storm structure and the response of the $\mathrm{Ku}$ and $\mathrm{Ka}$ bands to intense hailstorms.

\section{HIWRAP and ground-based radar observations of hailstorms}

\section{a. Storm C1 flight line}

\section{1) VerticAl CROSS SECTION ALONG ER-2 FLIGHT LINE}

To facilitate comparison between the HIWRAP Ku-/ Ka-band data and the S-band KOUN data, we have mapped KOUN data from scans in spherical radar coordinates to latitude, longitude coordinates for the ER-2 flight line as previously used in Heymsfield et al. (2000) and Tian et al. (2002). Figure 9a shows a vertical cross section of S-band reflectivity from KOUN volume scans between 0121 and 0125 UTC along the ER-2 flight track during 0122:44-0126:19 UTC (shown in Fig. 5). The storm top exceeded $16 \mathrm{~km}$ in both the KOUN scan (Fig. 9a) and HIWRAP reflectivity (Figs. 9b,c). An intense core observed by KOUN with reflectivity greater than $60 \mathrm{dBZ}$ and a horizontal dimension of about $10 \mathrm{~km}$ extends from the surface up to $11-\mathrm{km}$ altitude. This core is sloped toward the southeast with height and is consistent with the northwesterly surface-500-hPa vertical shear $\left(\sim 25 \mathrm{~m} \mathrm{~s}^{-1}\right.$ toward $\left.130^{\circ}\right)$ during the period. The motion of $\mathrm{C} 1$ was $\sim 4.4 \mathrm{~m} \mathrm{~s}^{-1}$ toward $150^{\circ}$ so that most of the observed tilt was due to shear rather than from storm advection during the time taken for the PPI scan sequence used in constructing Fig. 9a. This deep core of high reflectivity along with near-zero $Z_{\mathrm{DR}}$ reaching the surface is a clear indication of a hail shaft (Fig. 9d) (e.g., Bringi et al. 1986; Wakimoto and Bringi 1988). A $Z_{\mathrm{DR}}$ column up to $7.5 \mathrm{~km}$ to the south of the flight line suggests that liquid and mixed-phase hydrometeors were lofted to high altitudes, as will be discussed later. In this same region, HIWRAP reflectivity has significant attenuation. The reflectivities from the $\mathrm{Ku}$ and $\mathrm{Ka}$ bands are completely attenuated below 8 and $12 \mathrm{~km}$, respectively (Figs. 9b,c). The peak reflectivity through this region is $\sim 45 \mathrm{dBZ}$ for $\mathrm{Ku}$ band and $\sim 35 \mathrm{dBZ}$ for $\mathrm{Ka}$ band as compared with the $63 \mathrm{dBZ}$ observed at $\mathrm{S}$ band. This is not surprising since large hail would be in the Mie-scattering and highly attenuating region at $\mathrm{Ku}$ and Ka bands, as will be discussed further in section 5 .

The large upward Ku-band Doppler velocities from HIWRAP (Fig. 9e) have been corrected for aircraft motion. Doppler velocities by convention are positive downward (away from HIWRAP), but we have swapped 


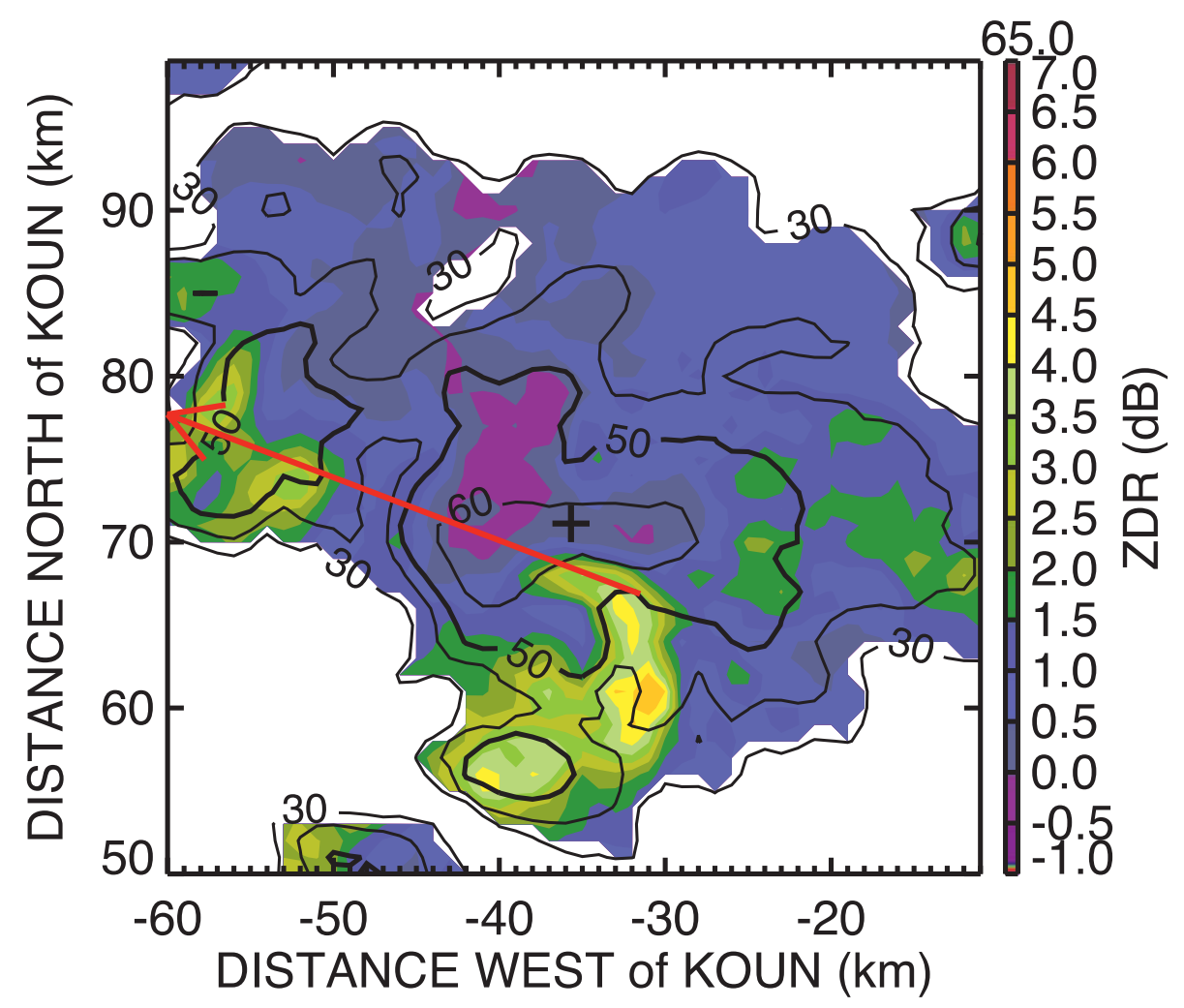

FIG. 5. Horizontal cross section at $3 \mathrm{~km}$ AGL at 0121 UTC 24 May. The black contours are KOUN reflectivity starting at $30 \mathrm{~dB} Z$ at $10-\mathrm{dB} Z$ intervals. The $Z_{\mathrm{DR}}$ values are color shaded, starting at $-1 \mathrm{~dB}$. The red line is the ER-2 flight track between 0121 and 0126 UTC. The maximum reflectivity is $65 \mathrm{dBZ}$ and is marked by a plus sign. Flight-line direction is from southeast to northwest.

the sign on the color bar so that positive Doppler velocities are upward. The Ka-band Doppler velocity (Fig. 9f) shows a structure that is similar to that of the $\mathrm{Ku}$ band in general except in the storm's core. A strong upward Doppler velocity core above $10 \mathrm{~km}$ AGL at $\sim 7$-km distance in Fig. 9e suggests an extremely strong updraft when the fall speed contribution is added (see section 5); Fig. 9f shows that the top of this updraft is above $10-\mathrm{km}$ altitude before attenuation, Mie scattering, and multiple scattering become significant. The Doppler velocities in this updraft profile are not continuous from the maximum near $11 \mathrm{~km}$ to the surface, which may be due either to the tilt of the updraft in or out of the vertical plane of the measurements or to large hail fall speeds below the updraft maximum. At $\mathrm{Ku}$ band, the signal is strong in this region and therefore the Doppler estimate should be reliable (see the appendix); Ka-band Doppler has more problems in this region, with many factors contributing to poor measurements. This situation includes even the possibility that the Ka-band Doppler is affected by multiple scattering similar to what was modeled by Battaglia et al. (2011) for the W band. Strong downward hydrometeor motions $\left(<-30 \mathrm{~m} \mathrm{~s}^{-1}\right)$ at higher altitudes are present to the northwest of the updraft core (distance 11-16 km in Fig. 9e). The spatial resolution ( $\sim 175 \mathrm{~m}$ at $10-\mathrm{km}$ altitude) of the Ka-band Doppler measurements (Fig. 9f) is $\sim 2.5$ times that of $\mathrm{Ku}$ band, and the Ka-band measurements show similar downward hydrometeor motions near this feature. Therefore, this feature is most likely due to a downdraft and/or high fall speeds rather than to other effects such as nonuniform beam filling (NUBF) that could bias the Doppler measurements (e.g., Tanelli et al. 2002).

\section{2) Averaged vertical profile}

We next examine the vertical structure near C1's core by averaging vertical profiles in the region between the two dashed lines in Fig. 9. Figure 10a shows mean profiles of reflectivity and the difference of the measured reflectivity at two frequencies (reflectivity at lower frequency minus the reflectivity at higher frequency). The best agreement between the reflectivity at the three frequencies occurs near cloud top $(>14 \mathrm{~km})$ since the ice particles are small and closer to Rayleigh scatterers for all three frequencies, and attenuation is small. Note that, although reflectivity at $\mathrm{S}$ band is larger than $60 \mathrm{dBZ}$, the 

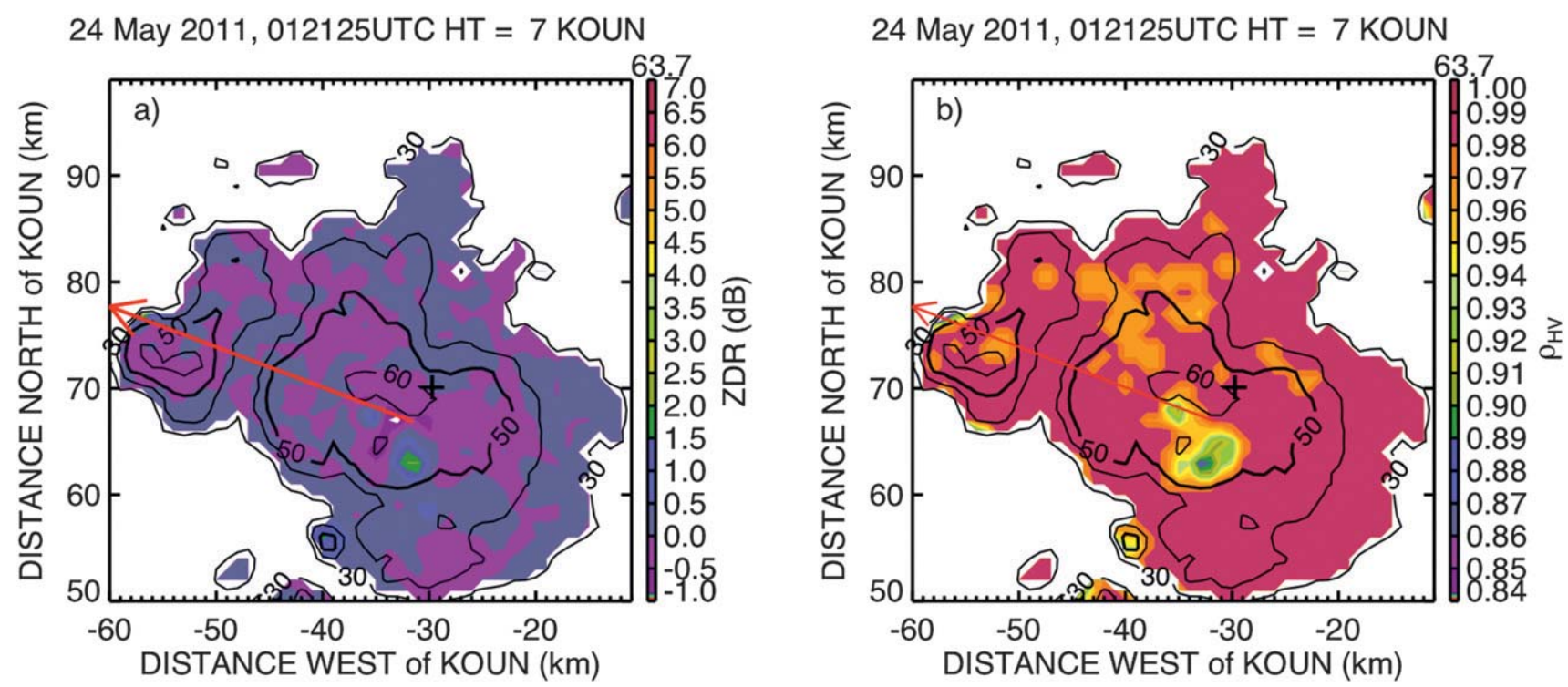

FIG. 6. Horizontal cross section of (a) $Z_{\mathrm{DR}}$ and (b) $\rho_{h v}$ at $7 \mathrm{~km}$ AGL at $0121 \mathrm{UTC} 24$ May. The black contours are KOUN reflectivity starting at $30 \mathrm{~dB} Z$ at $10-\mathrm{dB} Z$ intervals.

reflectivities at $\mathrm{Ku}$ and $\mathrm{Ka}$ bands at any level do not exceed $\sim 47$ and $\sim 34 \mathrm{dBZ}$ for this line, respectively. This difference is mostly due to Mie scattering at the very top of the high-reflectivity region and then a combination of Mie scattering, attenuation, and multiple scattering below. All of these effects are significantly worse at Ka band than at $\mathrm{Ku}$ band. As shown in Fig. 10a, the reflectivities at $\mathrm{Ku}$ and $\mathrm{Ka}$ band are 35 and $60 \mathrm{dBZ}$, respectively, lower than that of $\mathrm{S}$ band at $6-\mathrm{km}$ altitude. The Ka-band reflectivity becomes mostly attenuated below $\sim 5-\mathrm{km}$ altitude. Separating the effects of Mie scattering, attenuation, and multiple scattering in the current observations shown in Fig. 10a is difficult. Battaglia et al. (2011, their Fig. 4) show that multiple scattering artificially increases the reflectivity and could potentially enhance the value of the peak reflectivity. Battaglia et al. (2006) further suggest that multiple scattering could be an issue for GPM DPR at Ka band since the spaceborne radars have larger footprints. As a result, the enhancement could be as large as tens of decibels. HIWRAP has a much smaller footprint, and therefore the effect of multiple scattering is less significant.

Figure 10b again shows the strong updraft core with a peak Doppler value of $\sim 39 \mathrm{~m} \mathrm{~s}^{-1}$ at $11-\mathrm{km}$ altitude,

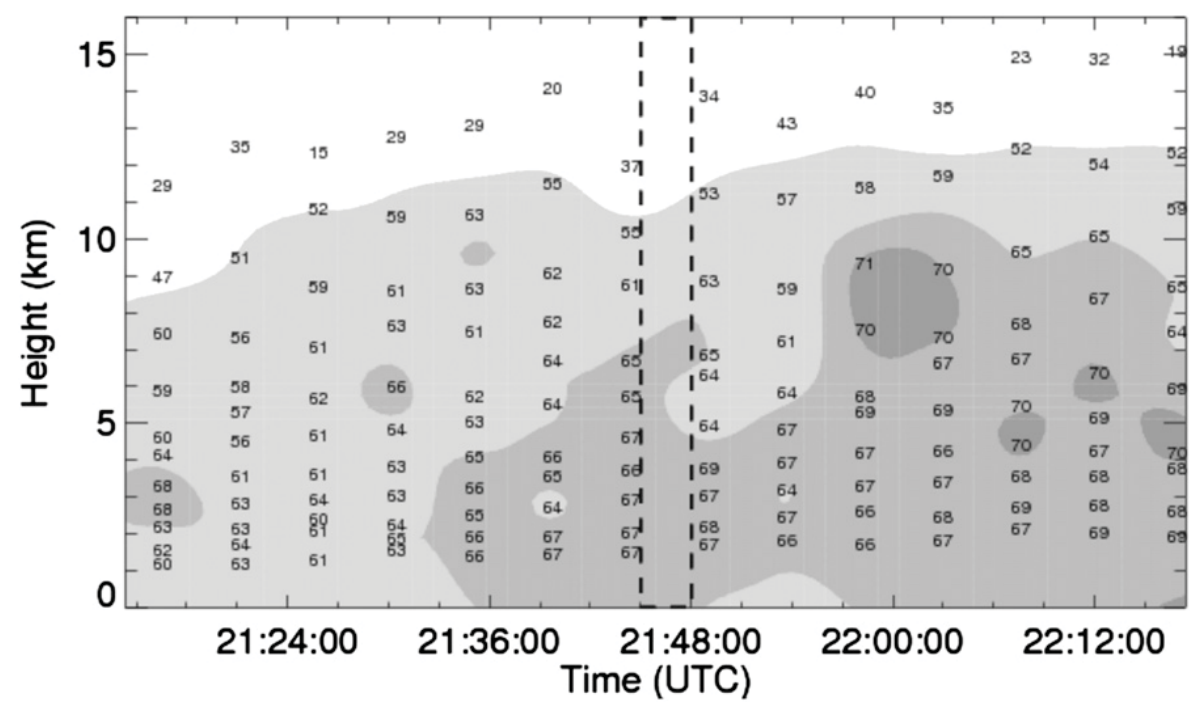

FIG. 7. Similar to Fig. 4 except that the Dodge City, Kansas (KDDC), radar was used to examine storm $\mathrm{C} 2$. 


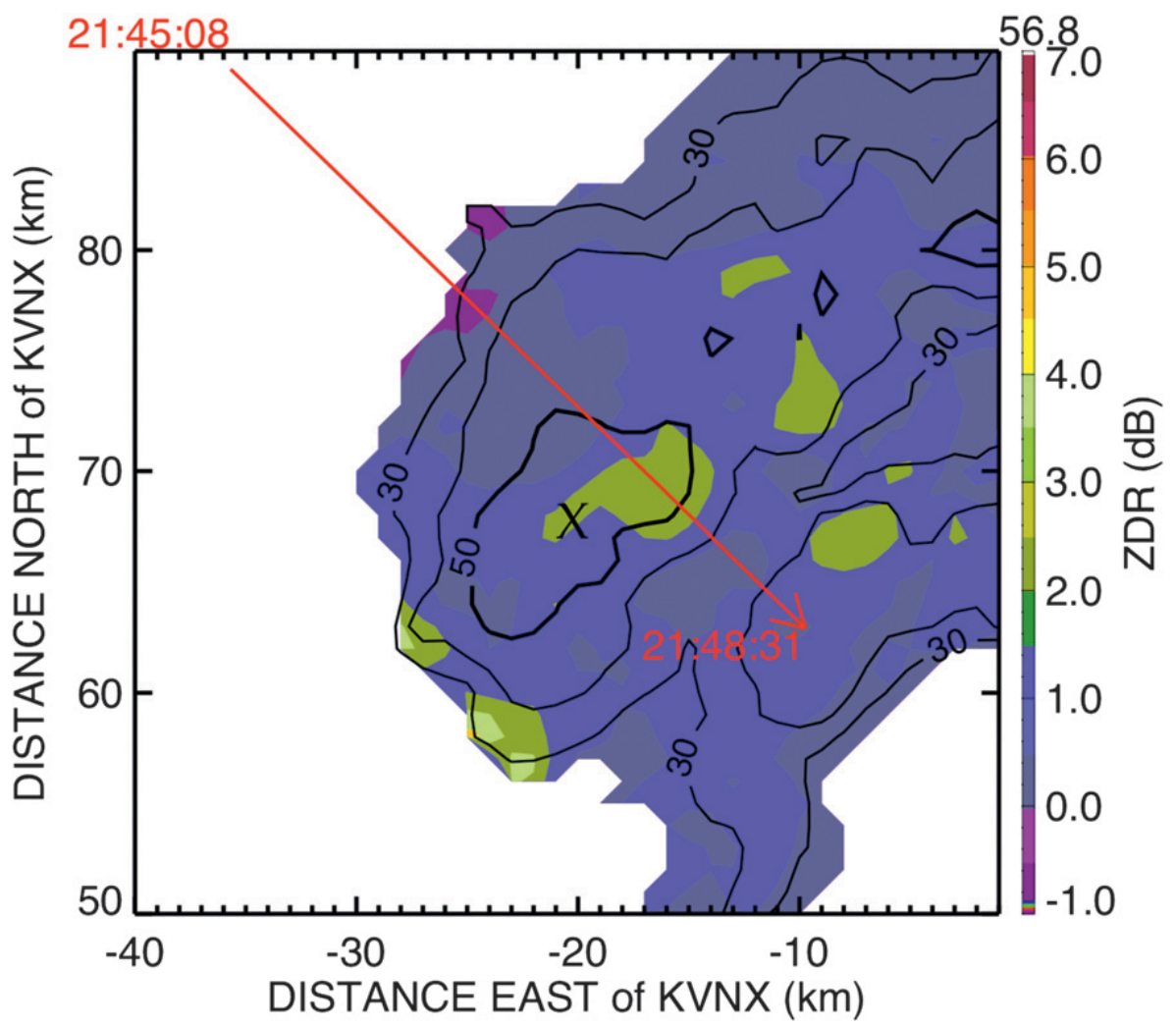

FIG. 8. Similar to Fig. 5, but at 2143 UTC 24 May and the black contours are KVNX reflectivity and the red line is the ER-2 flight track between 2145 and 2148 UTC. The maximum reflectivity is $65 \mathrm{dBZ}$ and is marked by an X.

where the corresponding Ku-band reflectivity is $\sim 45 \mathrm{dBZ}$ and the S-band reflectivity is $\sim 60 \mathrm{dBZ}$ (cf. Figs. 10a and $10 \mathrm{~b}$ ) in the updraft core region.

\section{3) VerticAl CROSS SECTION THROUGH $Z_{\mathrm{DR}}$ COLUMN}

Figure 11 shows a vertical cross section of KOUN measurements reconstructed from KOUN PPI volume scans between 0121 and 0125 UTC along the dashed line passing through the $Z_{\mathrm{DR}}$ column located south of the ER-2 flight track shown in Fig. 5. Similar to Fig. 9a, the $>60$-dBZ reflectivity core extending to the surface associated with near-zero $Z_{\mathrm{DR}}$ indicates a hailshaft. The positive $Z_{\mathrm{DR}}$ column at a distance of $6 \mathrm{~km}$ reaches up to $7.5 \mathrm{~km}$ (Fig. 11b) and is capped by a reduction of $\rho_{h v}$ (Fig. 11c). The higher value of $Z_{\mathrm{DR}}$ of $4 \mathrm{~dB}$ below the freezing level is probably due to the melting of hailstones. As recent observational and modeling studies show, the $Z_{\mathrm{DR}}$ column pinpoints the localization of a convective updraft, and its vertical extension is proportional to the updraft strength (e.g., Kumjian et al. 2012; Picca et al. 2010). Supercooled raindrops are usually responsible for relatively shallow $Z_{\mathrm{DR}}$ columns (1-2 km above freezing level, which is at $\sim 4.3 \mathrm{~km}$ in this case). Taller columns observed here usually signify that large graupel/hail particles are growing in the wet regime and that they are water coated, producing high $Z_{\mathrm{DR}}$ at midlevels in the updrafts. Of course, such wet growth is not possible at very low temperatures, and upper parts of strong updrafts do not produce $Z_{\mathrm{DR}}$ signatures at all. Wet growth usually manifests larger-size hail and is additionally marked by substantial depression of the cross-correlation coefficient at the levels at which the temperature is between $-10^{\circ}$ and $-20^{\circ} \mathrm{C}$ (Picca and Ryzhkov 2012). There is a strong indication that giant hail with sizes exceeding $5 \mathrm{~cm}$ is usually associated with strong $\rho_{h v}$ depression and slightly negative $Z_{\mathrm{DR}}$ above the melting layer (Kumjian et al. 2012).

\section{b. Storm C2 flight line}

Figure 12 shows the vertical cross section along the flight line in Fig. 8. The radar cloud top for this storm extended up to $15 \mathrm{~km}$ AGL, which is $\sim 2 \mathrm{~km}$ lower than for $\mathrm{C} 1$. Figure 12 indicates the appearance of a weaker storm than $\mathrm{C} 1$. The maximum reflectivities are high but barely reaching $60 \mathrm{dBZ}$ at $\mathrm{S}$ band (Fig. 12a). The Kuand Ka-band reflectivities (Figs. 12b,c) show an interesting "cap"-like reflectivity structure at $\sim 12 \mathrm{~km}$ 

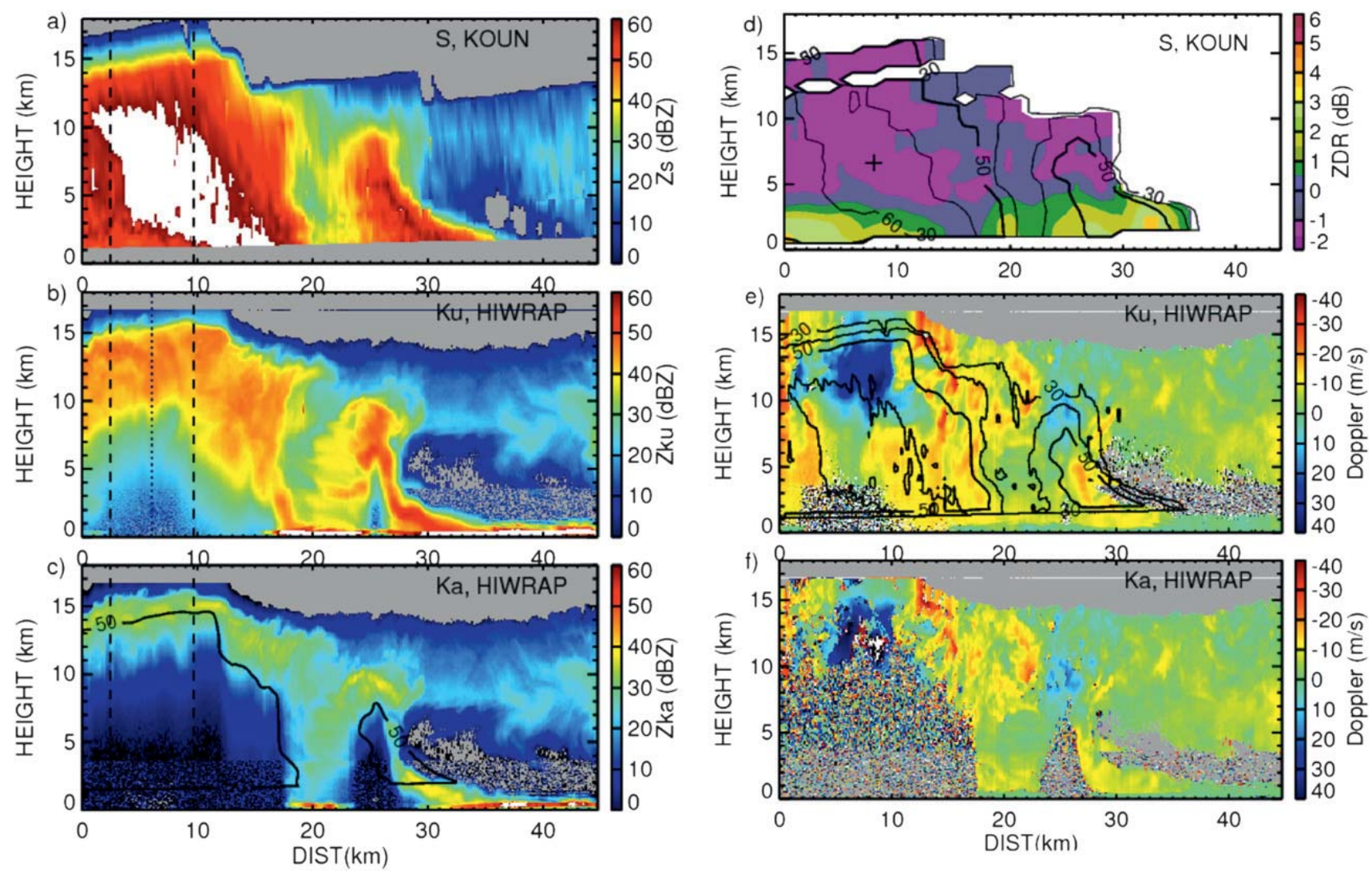

FIG. 9. Vertical cross section along the flight line at 0121-0126 UTC 24 May 2011, as shown in Fig. 1, for (a) S-band reflectivity from KOUN, HIWRAP reflectivities at (b) Ku and (c) Ka bands, (d) $Z_{\mathrm{DR}}$ with KOUN reflectivity contoured, and HIWRAP Doppler velocity at (e) $\mathrm{Ku}$ and (f) $\mathrm{Ka}$ bands. The contour lines are S-band reflectivity starting at $30 \mathrm{dBZ}$ with an interval of $10 \mathrm{~dB}$. The HIWRAP observations extend up to approximately $16-\mathrm{km}$ altitude because of the pulse compression used. The section is oriented from southeast to northwest. The plus sign in (d) indicates the location of the maximum reflectivity. The dashed vertical lines in (a)-(c) indicate the averaging region used in Fig. 10, below. The dotted vertical line in (b) is the center of this region.

AGL. The reflectivities at $\mathrm{Ku}$ and $\mathrm{Ka}$ bands are completely attenuated below 3 and $5 \mathrm{~km}$ AGL, respectively. The $Z_{\mathrm{DR}}$ does not have a distinctive hail signature (Fig. 12c) at lower levels during the overpass time. A strong positive Doppler velocity is noted in the storm's core that is associated with the updraft (Figs. 12,f), although these Doppler velocities are weaker than those in Fig. 9. The profiles in Fig. 13 also indicate that this storm is weaker than the $\mathrm{C} 1$ storm. The S-band reflectivity (Fig. 13a) barely reaches $55 \mathrm{dBZ}$, the Ku-band reflectivity peaks at $\sim 47 \mathrm{~dB} Z$, and the Ka band peaks at $\sim 37 \mathrm{~dB} Z$ at $12-\mathrm{km}$ altitude. The lower S-band reflectivity relative to $\mathrm{Ku}$ above $11 \mathrm{~km}$ is mainly due to the differences in volume-scan and overpass times and spatial resolutions between HIWRAP and KVNX. Doppler velocities are also somewhat different from C1, where peak upward motions (without fall speed added) of $25 \mathrm{~m} \mathrm{~s}^{-1}$ occur at a lower altitude between 4 and $8 \mathrm{~km}$.

Several regions of downward Doppler velocities $\left(<0 \mathrm{~m} \mathrm{~s}^{-1}\right)$, indicative of downdrafts or large fall speeds, are present at higher altitudes surrounding the main updraft region of $\mathrm{C} 2$. These were higher than for $\mathrm{C} 1$, with a minimum just lower than $-30 \mathrm{~m} \mathrm{~s}^{-1}$ at $\sim 10.5 \mathrm{~km}$ AGL and 22-km distance. Similar to what was observed in C1, the Ka-band Doppler (Fig. 12f) showed downdraft features that are similar to those of the Ku-band Doppler (Fig. 12e), and therefore NUBF Doppler biases do not appear to be responsible for this feature.

\section{Interpretations from the observations}

\section{a. Summary of observations}

The analysis of MC3E hailstorms with HIWRAP and polarimetric measurements has shown several prominent features: 1) strong updrafts are suggested by the Doppler velocities, with $39 \mathrm{~m} \mathrm{~s}^{-1}$ at $10.7 \mathrm{~km}(250 \mathrm{hPa})$ and $30 \mathrm{~m} \mathrm{~s}^{-1}$ at $13.7 \mathrm{~km}(160 \mathrm{hPa})$ in storm $\left.\mathrm{C} 1,2\right)$ large attenuation is observed in $\mathrm{C} 1$ and $\mathrm{C} 2,3)$ a tall $Z_{\mathrm{DR}}$ column up to $7.5 \mathrm{~km}$ is accompanied by a depression of $\left.\rho_{h v}, 4\right)$ S-band reflectivities exceed $70 \mathrm{~dB} Z$, with $60 \mathrm{~dB} Z$ extending up to $10.5-\mathrm{km}$ altitude, and 5) the $\mathrm{Ku}-$ and 

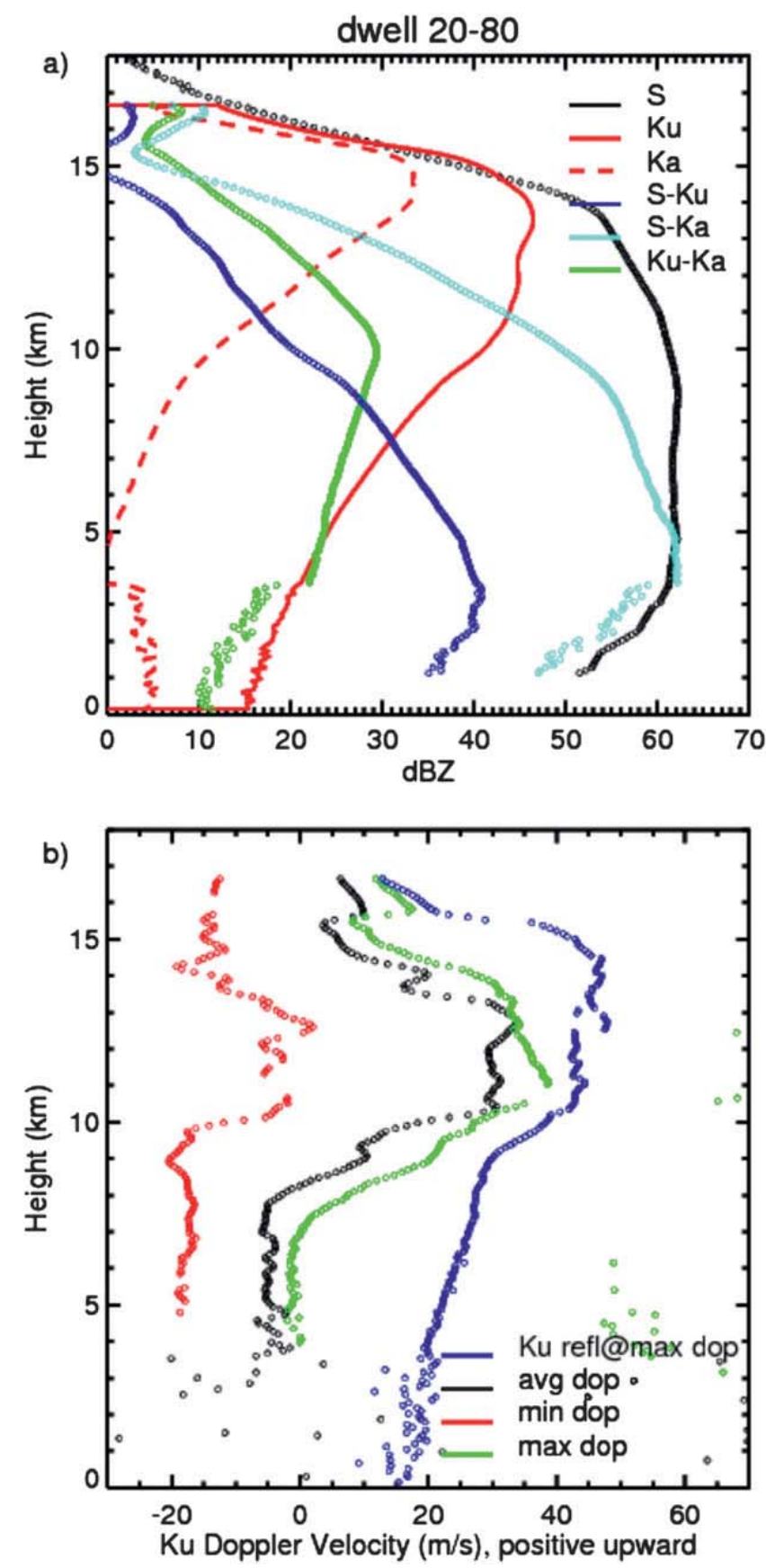

FIG. 10. Profiles corresponding to Fig. 9: (a) averaged profile of reflectivity at three frequencies $(\mathrm{S}, \mathrm{Ku}$, and $\mathrm{Ka})$ and reflectivity differences between the two frequencies $(\mathrm{S}-\mathrm{Ku}, \mathrm{S}-\mathrm{Ka}$, and $\mathrm{Ku}-\mathrm{Ka})$ and (b) Ku-band Doppler velocity at $\sim 5$-km distance in Fig. 9, along with the minimum and maximum Doppler velocities within the same section. Average profiles use 30 profiles in the section between the two vertical dashes in Fig. 9. The Ku-band reflectivity at the location of maximum Doppler velocity is also plotted in (b) (blue line).

Ka-band reflectivities in $\mathrm{C} 1$ and $\mathrm{C} 2$ decrease significantly below $12-14-\mathrm{km}$ altitude, relative to the S-band reflectivity. There are a number of questions related to both the storm microphysics and the use of spaceborne radar. Here, we address two of them: 1) What are the
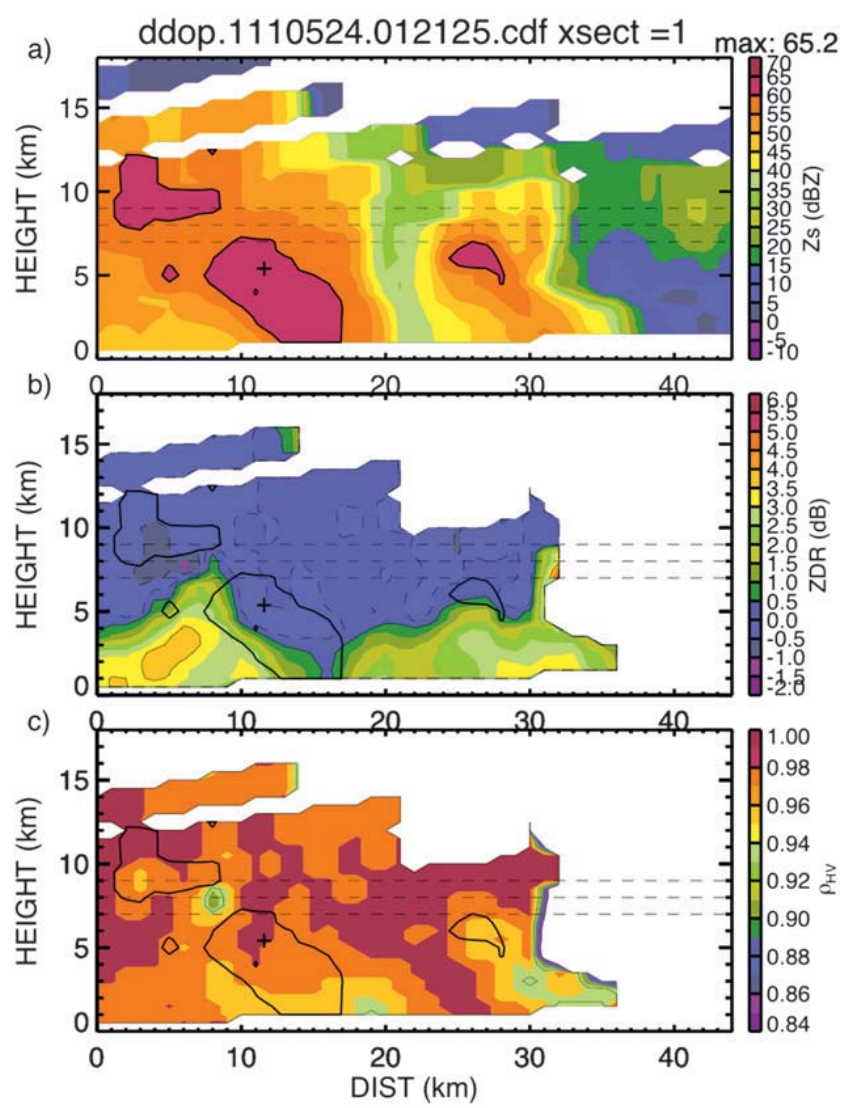

FIG. 11. Vertical cross sections of (a) S-band reflectivity, (b) $Z_{\mathrm{DR}}$, and (c) $\rho_{h v}$ from KOUN volume scans between 0121 and 0125 UTC along a line $1.5 \mathrm{~km}$ south of the ER-2 flight line. For reference, horizontal dashed lines show 7-, 8-, and 9-km heights. The black contours show the $60-\mathrm{dB} Z$ reflectivity.

magnitudes of the updrafts? 2) Are the ice particles at the higher altitudes graupel, or are they small or large hail? In the following, we discuss the current observations to provide insight on these questions.

\section{b. Updraft magnitudes from Doppler observations}

Reflectivity-weighted fall speeds are required to estimate the vertical motions from the Doppler measurements. Ulbrich (1977) calculated reflectivity-weighted hail fall speeds for a range of wavelengths from $S$ band $(10 \mathrm{~cm})$ down to $X$ band $(3.2 \mathrm{~cm})$, for dry and wet hail with density $0.917 \mathrm{~g} \mathrm{~cm}^{-3}$, and for representative exponential size distributions that were based on empirical observations. A simplified $v_{T}=A^{\prime} Z_{e}^{b}$ is given for dry or water-coated hail by Eq. (11) in Ulbrich (1977), where $A^{\prime}$ and $b$ are coefficients in his Table 2 , and $Z_{e}$ is the equivalent reflectivity. Coefficient $A^{\prime}$ is normalized to $N_{0}=100 \mathrm{~m}^{-3}$ in the exponential distribution so that it is not sensitive to its fluctuations. Ulbrich states that the $\boldsymbol{v}_{T}$ is not very sensitive to wavelength for dry and watercoated hail. For the 60-dBZ S-band reflectivities near the Doppler velocity maximum in Fig. 9a, S-band $v_{T}$ for 

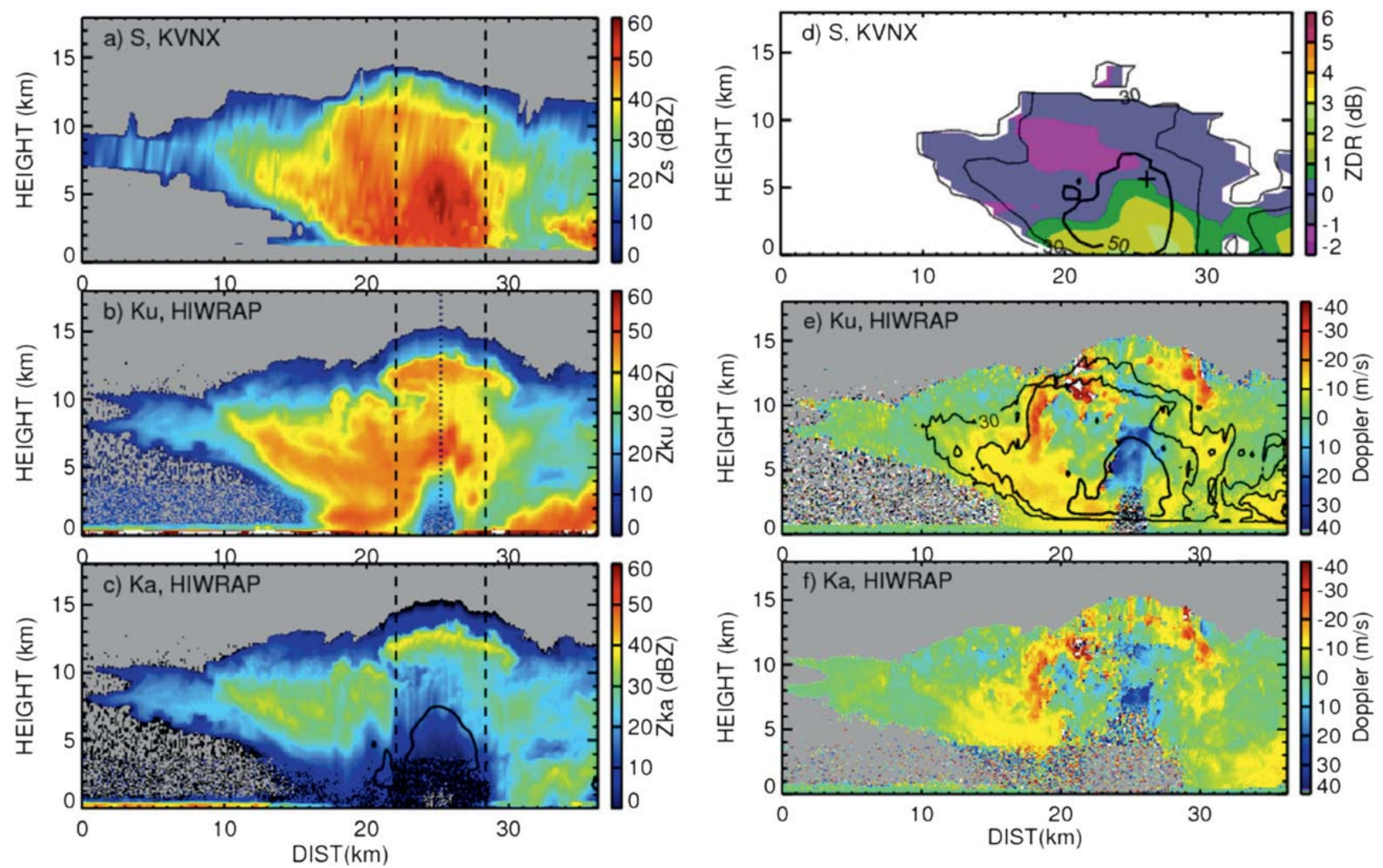

FIG. 12. As in Fig. 9, but for a flight line between 2145 and 2148 UTC 24 May, as shown in Fig. 8.

dry hail is $20.1 \mathrm{~m} \mathrm{~s}^{-1}$ at the $1000-\mathrm{hPa}$ level; the corresponding X-band $v_{T}$ is $20.9 \mathrm{~m} \mathrm{~s}^{-1}$. Above the surface, $v_{T}$ must be corrected for decreased air density with altitude by an approximate factor of $\left[\rho_{0} / \rho(z)\right]^{0.45}$, where $\rho(z)$ and $\rho_{0}$ are the densities at height $z$ and at $1000 \mathrm{hPa}$, respectively (Beard 1985). This would suggest an increase in Ulbrich's fall speed estimate by a factor of $\sim 1.5$ or $\sim 30 \mathrm{~m} \mathrm{~s}^{-1}$ at $250 \mathrm{hPa}(10.7-\mathrm{km}$ altitude). The above correction was based on rain, and more recent work has shown an exponent closer to 0.4 for snow and graupel so that there might be a small reduction in fall speed magnitude (A. Heymsfield 2012, personal communication). A fall speed of $30 \mathrm{~m} \mathrm{~s}^{-1}$ and maximum Doppler velocity of $39 \mathrm{~m} \mathrm{~s}^{-1}$ would give a maximum updraft of $69 \mathrm{~m} \mathrm{~s}^{-1}$ (Doppler velocity $+v_{T}$ ).

Particles with lower density will have a smaller fall speed when compared with solid ice. The World Meteorological Organization defines hail as solid ice $\left(0.91 \mathrm{~g} \mathrm{~cm}^{-3}\right)$ and generally larger than $5 \mathrm{~mm}$, whereas graupel has a lower density $\left(<0.4 \mathrm{~g} \mathrm{~cm}^{-3}\right)$ and is less than $5 \mathrm{~mm}$; graupel is sometimes referred to as small hail. There are a number of reports in the literature of lower-density hail with values as low as $0.4 \mathrm{~g} \mathrm{~cm}^{-3}$ for 1-cm hail (e.g., Knight and Heymsfield 1983). If lowerdensity hail were present, it would still have a significant fall speed (e.g., Fig. 6 in Knight and Heymsfield 1983), although it is complicated to assess the overall impact on $v_{T}$ given that the size distribution is unknown. Reducing the $v_{T}$ estimate by half would still provide an updraft of $54 \mathrm{~m} \mathrm{~s}^{-1}$.

There are limited data to corroborate these peak updraft estimates. Musil et al. (1991) presented measurements at 6-km altitude from an armored T-28 aircraft in severe Montana hailstorms, and they estimated up to $53 \mathrm{~m} \mathrm{~s}^{-1}$ updrafts and $18 \mathrm{~m} \mathrm{~s}^{-1}$ downdrafts (Table 2 in Musil et al. 1991). Their updraft and downdraft core sizes tended to increase with updraft magnitude; the $53 \mathrm{~m} \mathrm{~s}^{-1}$ updraft case had a core $15 \mathrm{~km}$ wide that contained 5-cm hail. Their observed updrafts tended to be stronger than downdrafts. Their most intense case on 2 August 1981 had 5-cm hail with a hailstone concentration of 30 hailstones per meter cubed. Bluestein et al. (1988) studied a dryline supercell in the Texas Panhandle that was tornadic and producing hail. The updraft speeds estimated from sounding ascent rates were $35-40 \mathrm{~m} \mathrm{~s}^{-1}$ between 6- and 7-km altitude, with a peak value of $38 \mathrm{~m} \mathrm{~s}^{-1}$ at $8 \mathrm{~km}$. Nelson (1983) calculated a $50 \mathrm{~m} \mathrm{~s}^{-1}$ updraft in an Oklahoma hailstorm from a dual-Doppler analysis. The updraft magnitudes (54-69 $\mathrm{m} \mathrm{s}^{-1}$ ) obtained in this study are also consistent with the large CAPE in 

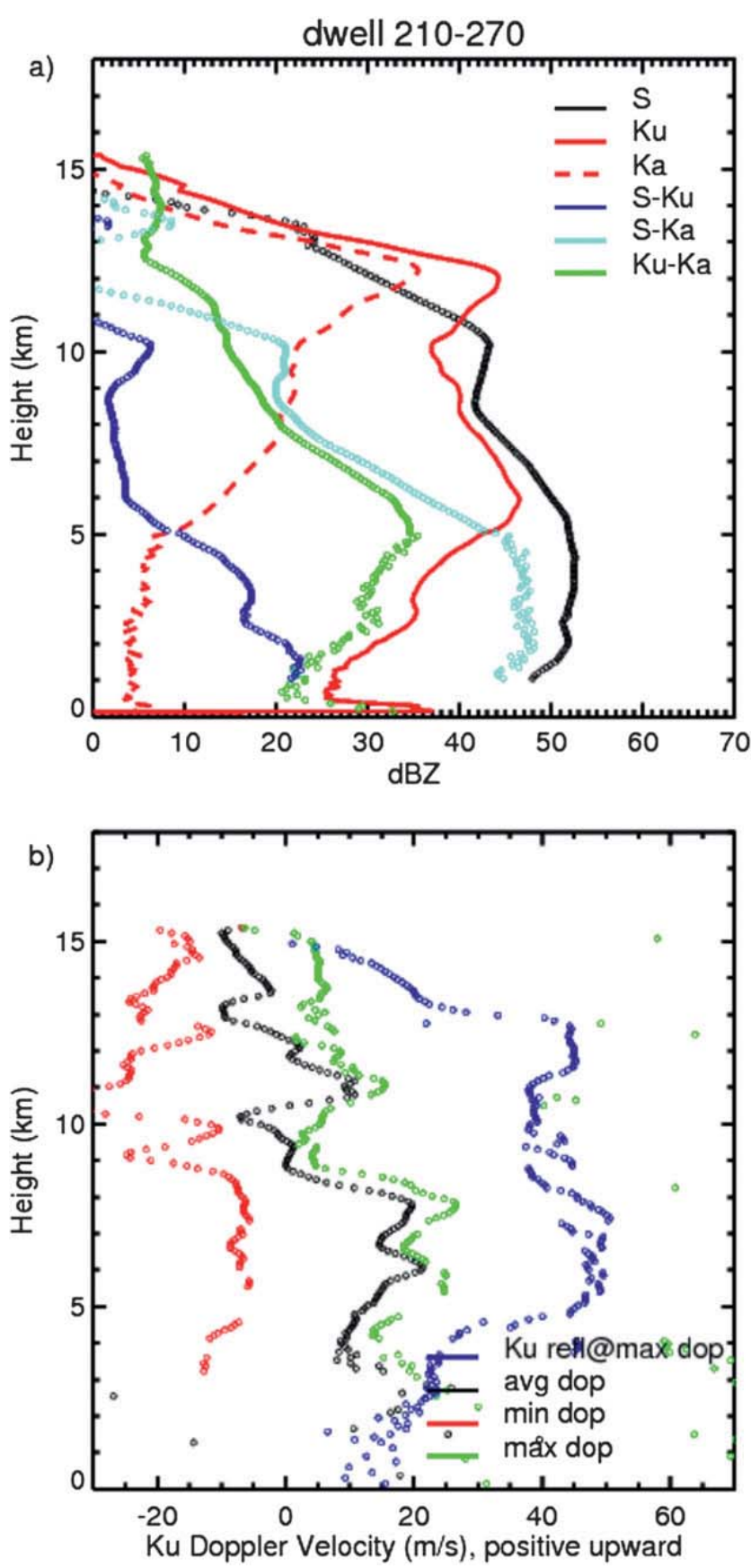

FIG. 13. As in Fig. 10, but for a line between 2145 and 2148 UTC 24 May.

the environment (section 3) and the nearly 4-km overshoot of the equilibrium level by the storm top.

\section{c. Hail scattering and attenuation}

Airborne radar measurements at $\mathrm{Ku}$ and $\mathrm{Ka}$ bands from APR-2 have been used for testing spaceborne dual-wavelength rain-retrieval algorithms (e.g., Liao and Meneghini 2011; Grecu et al. 2011; Le and Chandrasekar 2012). Most of these studies have focused on stratiform rain because of its relatively simple vertical structures. The scattering properties of snow aggregates above the melting layer, mixed phase inside the melting layer, and raindrops below are better understood from field experiments and theoretical computations. Comparable studies have not been made for hail at $\mathrm{Ku}$ and $\mathrm{Ka}$ bands, mainly because of the lack of observations in severe storms, especially over land with good coverage of ground-based radar. In the following, we provide some insight on the hail reflectivities for HIWRAP and GPM and use the WSR-88D S-band wavelength as a reference, similar to the presentation in section 4 . We are particularly interested in whether the $\mathrm{Ku}$ - and $\mathrm{Ka}$-band observations can be used to detect the presence of hail in future satellite measurements.

The focus here is on obtaining a general sense of the behavior of large hail in the 10-12-km-altitude region of the storms where the HIWRAP reflectivities at $\mathrm{Ku}$ and Ka bands undergo rapid departures from the S-band reflectivities and where temperatures are sufficiently low. To understand fully the vertical profiles at $\mathrm{Ku}$ and Ka bands in such a hailstorm, we need to consider not just hail but also graupel with different shapes, densities, and particle size distributions, which is beyond the scope of this paper. The assumption is made that dry hail with density $0.917 \mathrm{~g} \mathrm{~cm}^{-3}$ is present in this region. ${ }^{2}$ Scattering calculations are performed at the three frequencies ( $\mathrm{S}$, $\mathrm{Ku}$, and $\mathrm{Ka}$ band) using Mie theory with the assumption of a monodisperse distribution of dry spherical hailstones up to $6 \mathrm{~cm}$ and a temperature of $-30^{\circ} \mathrm{C}$. Figure 14 shows calculations of the radar reflectivity, the one-way attenuation coefficient normalized by number concentration $N$, and the dual-frequency ratio (DFR $=Z_{f 1}-Z_{f 2}$, where the subscripts indicate the radar frequency, with $f 1<f 2$ ). DFR is independent of number concentration. Given that we do not know the hail sizes or concentrations within the updraft regions, Fig. 14 conveys the essential characteristics of the hailstone scattering.

Figure 14a shows that reflectivities at the three frequencies depart significantly from each other for hail of $>0.5 \mathrm{~cm}$ in diameter. The reflectivity of $\mathrm{Ka}$ band is lower than those at $\mathrm{Ku}$ and $\mathrm{S}$ bands. This is apparent in the observations, for which reflectivities are never higher than $35 \mathrm{~dB} Z$ at $\mathrm{Ka}$ band and $55 \mathrm{dBZ}$ at $\mathrm{Ku}$ band. Note that the S-band reflectivities also depart from Rayleigh

\footnotetext{
${ }^{2}$ The environmental air temperature is approximately $-40^{\circ} \mathrm{C}$ $\left(-45^{\circ} \mathrm{C}\right)$ from a representative sounding at $10-\mathrm{km}$ altitude from OUN (LMN) at 0000 UTC (1500 UTC) on 24 May 2011 for the C1 (C2) overpass, and the undiluted lifted parcel temperature is $\sim-35^{\circ} \mathrm{C}$. The expected air temperatures are sufficiently low to ensure that all particles are frozen above $10-\mathrm{km}$ altitude. Most raindrops freeze at much lower altitudes.
} 

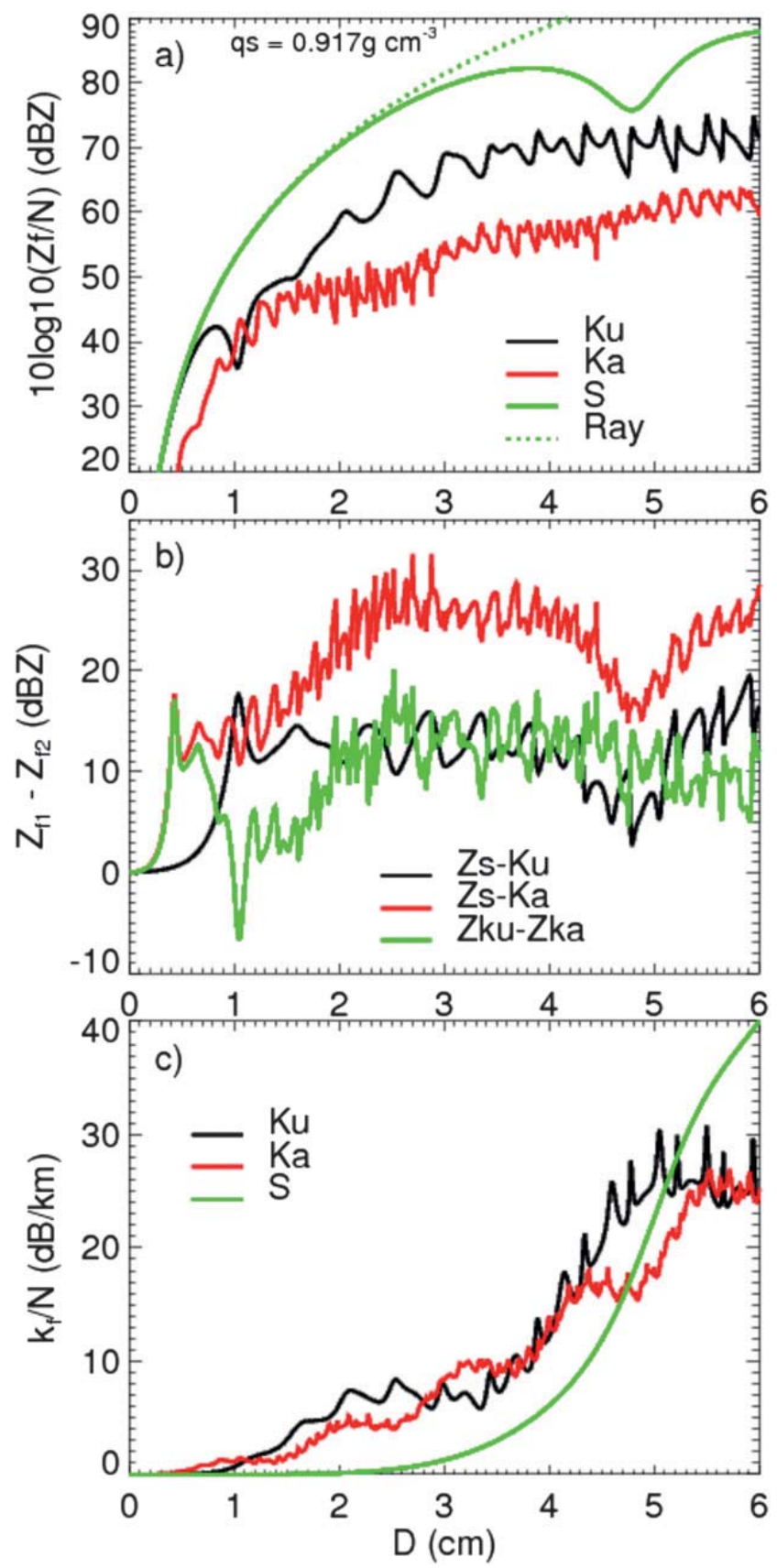

FIG. 14. Mie calculation for monodispersed hail size distribution, assuming ice density of $0.917 \mathrm{~g} \mathrm{~cm}^{-3}$, for (a) $Z_{f} / N$, (b) $Z_{f 1}-Z_{f 2}$, and (c) $k_{f} / N$ as a function of ice particle size, where $Z_{f}, k_{f}$, and $Z_{f 1}-Z_{f 2}$ are the reflectivity, one-way attenuation coefficient, and difference of the reflectivity at two different radar frequencies $(f 1>$ $f 2$ ), respectively, and $N$ is the concentration of monodispersed particles. In (a) and (c), solid black, red, and green curves are for $\mathrm{Ku}, \mathrm{Ka}$, and $\mathrm{S}$ bands, respectively. In (b), red, black, and green curves are for $Z_{S}-Z_{\mathrm{Ku}}, Z_{S}-Z_{\mathrm{Ka}}$, and $Z_{\mathrm{Ku}}-Z_{\mathrm{Ka}}$, respectively.

scattering for hailstones of $2 \mathrm{~cm}$ and larger. The DFR (Fig. 14b) is more complex. For hail diameters larger than $2 \mathrm{~cm}$, the DFR is larger than $10 \mathrm{~dB}$ for $Z_{S}-Z_{\mathrm{Ku}}$ and $Z_{\mathrm{Ku}}-Z_{\mathrm{Ka}}$, and $15 \mathrm{~dB}$ for $Z_{S}-Z_{\mathrm{Ka}}$. Between 0.5 and $2 \mathrm{~cm}$, DFR has a negative minimum near $1 \mathrm{~cm}$ for
$Z_{\mathrm{Ku}}-Z_{\mathrm{Ka}}$ and a large $17-\mathrm{dB}$ peak near $1-\mathrm{cm}$ size. This result illustrates why size distribution knowledge is so critical for understanding the hail DFR.

Attenuation at $\mathrm{Ku}$ and $\mathrm{Ka}$ bands (Fig. 14c) shows a much more complicated behavior, with the two curves crossing at about 1, 3, and $4 \mathrm{~cm}$. For hail sizes of less than $\sim 1 \mathrm{~cm}$, attenuation at $\mathrm{Ka}$ band is larger than at $\mathrm{Ku}$ band. This trend is reversed for hail sizes between $\sim 1.2$ and $3 \mathrm{~cm}$, however, and between 4.5 and $5.5 \mathrm{~cm}$. Note that for hail sizes of $\sim 4 \mathrm{~cm}$ attenuation between the $\mathrm{Ku}$ and $\mathrm{Ka}$ bands are comparable.

Large dry hailstones with diameters of more than $5 \mathrm{~cm}$ attenuate more at $\mathrm{S}$ band than at $\mathrm{Ku}$ and $\mathrm{Ka}$ bands. This is because at these sizes attenuation is caused mostly by scattering rather than by absorption. Attenuation at $\mathrm{S}$ band in hailstorms is rarely observed (A. Ryzhkov 2012, personal communication), however, because of the significantly higher concentration of smaller hailstones or graupel for which attenuation at $\mathrm{S}$ band is much lower. Therefore, the integrated attenuation at $\mathrm{S}$ band is dramatically smaller. In a similar way, hailstones with diameters larger than $3 \mathrm{~cm}$ attenuate more at $\mathrm{Ka}$ band than at $\mathrm{Ku}$ band, but observed Ka-band attenuation is higher than that at $\mathrm{Ku}$ band. Assuming different hail densities or water coating on the hail will greatly modify the behavior of these curves.

Figure 15 shows the $Z_{\mathrm{Ku}}-Z_{\mathrm{Ka}}$ for the $\mathrm{C} 1$ and $\mathrm{C} 2$ overpasses, where regions with $>14 \mathrm{~dB}$ are shaded white. The most striking feature is that the large DFR values are near $14 \mathrm{~km}(12 \mathrm{~km})$ for $\mathrm{C} 1(\mathrm{C} 2)$. The highest portions of this high-DFR region $(>14 \mathrm{~dB})$ are in the regions of strongest inferred updrafts from the Doppler velocities. The updraft regions likely have the highest total ice mass. The extent to which the high-DFR region indicates hail size and whether graupel is present is ambiguous, however, because of the complex nature of the hail scattering and attenuation, as mentioned previously. It would take extremely high concentrations of graupel to account for the $50+\mathrm{dB} Z$ observed above $10-\mathrm{km}$ altitude at $\mathrm{Ku}$ band in the storm cores. It is certainly possible, though, that there are mixtures of hail and graupel in this region. What is also of interest is that these large DFR values also extend to lower altitudes. For example, the cell in Fig. 9b (distance $25 \mathrm{~km}$ ) has a large DFR value present up to $8-\mathrm{km}$ altitude. In those regions, supercooled cloud drops, unfrozen rain, graupel, or recirculated hail could be present at this level $\left(-20^{\circ} \mathrm{C}\right)$. Certainly any mixed phase, wet aggregates, or graupel at lower altitudes would cause a large DFR. Differential attenuation between the two wavelengths contributes to this persistent large DFR, especially farther into the core. Further study is needed to determine the usefulness of $\mathrm{DFR}$ at $\mathrm{Ku}$ and $\mathrm{Ka}$ bands for hail detection. 

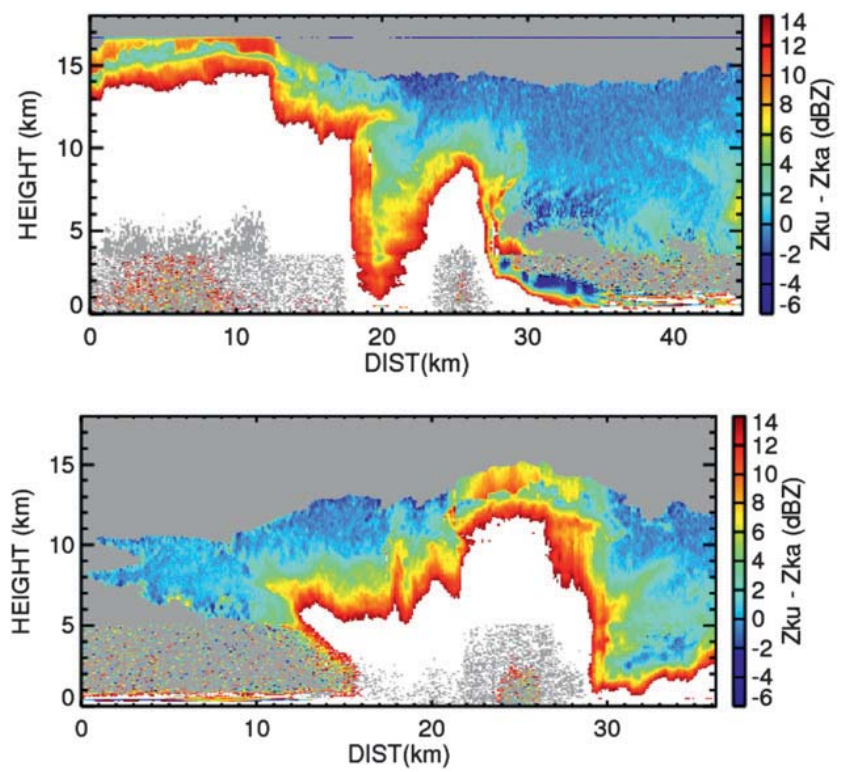

FIG. 15. The Ku-/Ka-band DFR $\left(Z_{\mathrm{Ku}}-Z_{\mathrm{Ka}}\right)$ for (top) $\mathrm{C} 1$ and (bottom) C2. The white-shaded region shows DFR $>14 \mathrm{~dB}$.

\section{Conclusions}

New dual-frequency (Ku and Ka bands) nadir-pointing radar measurements from HIWRAP mounted on the ER-2 aircraft have been obtained from severe hailstorms in Oklahoma and Kansas. These measurements are at frequencies that are similar to those of the TRMM PR (Ku band) and the upcoming GPM DPR (Ku and Ka bands). For GPM measurements, it is important to understand the dual-frequency radar characteristics in a wide variety of thunderstorm types and intensities globally. There is a wide range of vertical structures in convection because of varying updraft characteristics, microphysical composition such as hail or graupel, and their horizontal dimensions. This paper looks at moreextreme convection cases in the southern Great Plains. What are the limitations of spaceborne-radar measurements from GPM in strong midlatitude convection and what information can we expect to retrieve? Aircraft overflights of two strong hailstorms have provided not only storm structure but also implications of these kinds of storms for satellite measurements. Updrafts in severe storms have been previously estimated from S-band ground-based multi-Doppler analyses, inferred from observed soundings, or-less frequent-obtained from direct in situ aircraft measurements. Data from storms C1 and $\mathrm{C} 2$ have inferred updrafts possibly exceeding $50-60 \mathrm{~m} \mathrm{~s}^{-1}$ for $\mathrm{C} 1$ and $>35 \mathrm{~m} \mathrm{~s}^{-1}$ for $\mathrm{C} 2$. The $\mathrm{C} 1$ updraft magnitude is slightly higher than the strongest updrafts reported in the literature. The observed updraft is capable of supporting multicentimeter-size hail at higher altitudes. The $Z_{\mathrm{DR}}$ column height $(7.5 \mathrm{~km}$ AGL, or $\sim 3.2 \mathrm{~km}$ above the freezing level) corresponding to extreme updraft speeds is consistent with the theoretical modeling of Kumjian et al. (2012).

The reflectivities at $\mathrm{Ku}$ and $\mathrm{Ka}$ bands from HIWRAP exhibited large Mie scattering, high attenuation rates, and likely multiple scattering in cores of both storms. As a result, the maximum reflectivities observed were $35 \mathrm{dBZ}$ at $\mathrm{Ka}$ band and $45 \mathrm{dBZ}$ at $\mathrm{Ku}$ band, whereas the values at $\mathrm{S}$ band were sometimes as high as $70 \mathrm{dBZ}$ in the same regions. This is important for TRMM or GPM measurements since the peak heights of reflectivity levels such as $50 \mathrm{~dB} Z$ are often used to infer updraft strength in the absence of Doppler measurements. This procedure may result in ambiguity in interpretation since a 50-dBZ echo height at $\mathrm{Ku}$ band may actually be a much higher reflectivity. Calculations with simplistic hail assumptions (dry, spherical, and monodisperse) show that Mie effects become more significant for hail sizes of approximately $1 \mathrm{~cm}$ and above for $\mathrm{Ku}$ - and $\mathrm{Ka}$-band measurements. The DFR ( Ku - Ka) exceeds $14 \mathrm{~dB}$ near the top of the highreflectivity region at $\mathrm{S}$ band $(10-12-\mathrm{km}$ altitude) where Mie effects, attenuation, and multiple scattering all are likely significant. While this DFR information in itself may not indicate a unique determination of the ice particle characteristics (hail or graupel), it may be useful for the spaceborne measurements for differentiating a $50-\mathrm{dB} Z$ storm from a 70-dBZ storm. We have not focused on DFR interpretation at lower altitudes in the ice region where there are large variations in hydrometeor type (snow, graupel, hail, cloud, and supercooled raindrops) because of their complexity.

The horizontal extent of the SGP hailstorms is often 10-20 $\mathrm{km}$ across and would be detected by the GPM DPR with the 5-km GPM DPR spatial resolution. If processes such as multiple scattering are indeed important in the aircraft measurements, they will be much worse in the measurements from GPM because of its larger footprints. Further modeling calculations will be required to assess these kinds of complications, as well as the general utility of dual-frequency measurements in convection. Future work will examine a variety of convective intensities along with more-realistic modeling of the scattering properties such as in the modeling framework provided by Tanelli et al. (2011) that deals with single and multiple scattering.

Acknowledgments. This work was supported by the GPM Ground Validation (Drs. Matt Schwaller and Walt Petersen) and by NASA Precipitation Measuring Mission (PMM) funding. The U.S. DOE ARS was a major contributor in providing the infrastructure for MC3E. Acknowledgment is given to the NASA Dryden ER-2 group that expeditiously integrated HIWRAP onto the ER-2 
and conducted the flights. HIWRAP was funded under the NASA Instrument Incubator Program as a new technology instrument development. The authors thank the anonymous reviewers for their thorough comments. We thank Dr. Andrew Heymsfield for advice on the hail terminal velocities and Prof. Ramesh Srivastava and Dr. Alexander Ryzhkov for insightful discussions on radar hail observations and scattering aspects; Dr. Simone Tanelli provided insightful comments on the manuscript, particularly with regard to multiple-scattering processes. We also thank Dr. Stephen Guimond for his comments on the manuscript, Mr. Martin Perrine and Mr. Michael Coon for engineering support, and Dr. Amber Emory for field support and initial analysis.

\section{APPENDIX}

\section{Accuracy of Doppler Measurements in Updraft Regions}

For Doppler measurements, adjacent pulses must be correlated. The decorrelation time is given by $\tau_{i}=2 \lambda / \sigma_{v}$ [Sauvageot 1992, his Eq. (1.104)] and must be larger than the interpulse time $T_{s}=1 / \mathrm{PRF}$, where $\lambda$ is the radar frequency, $\sigma_{v}$ is the target spectral width, and PRF is the pulse repetition frequency. If we use $\sigma_{v}=10 \mathrm{~m} \mathrm{~s}^{-1}$ as our worst case, then $\tau_{i}$ is $\sim 4.4 \mathrm{~ms}$ at $\mathrm{Ku}$ band and $1.8 \mathrm{~ms}$ at Ka band. Since $T_{s}$ is $0.22 \mathrm{~ms}$ for both HIWRAP frequencies at the higher PRF $(4516 \mathrm{~Hz})$, the adjacent pulses are correlated as required for a Doppler measurement at $\mathrm{Ku}$ and $\mathrm{Ka}$ bands for the more severe conditions in the updraft cores. Note there is also decorrelation that is due to the aircraft motion, expressed by $\tau_{i}=0.57 \lambda /\left(V \vartheta_{B}\right)$ [Meneghini and Kozu 1990; their Eq. (2.82)], where $V$ is the platform motion and $\vartheta_{B}$ is the half-power antenna beamwidth from Table 1 . This decorrelation time is $\sim 1.4 \mathrm{~ms}(1.8 \mathrm{~ms})$ for $\mathrm{Ku}$ band ( $\mathrm{Ka}$ band), assuming an aircraft motion of $160 \mathrm{~m} \mathrm{~s}^{-1}$ so that adjacent pulses are still correlated at both frequencies.

Evaluation of $\sigma_{v}$ from the observations is required to understand the magnitude of the errors in Doppler measurements. Various factors such as turbulence, shear, platform motion, and particle fall speeds all contribute to $\sigma_{v}$, especially in the most turbulent regions such as in intense updrafts. The $\sigma_{v}$ is calculated according to Eq. (6.27) in Doviak and Zrnić (1993), using estimates of the autocorrelation coefficient and the signal after noise removal:

$$
\sigma_{v}=\frac{\lambda}{2 \pi T \sqrt{2}}\left|\ln \left(\frac{S}{\left|R_{1}\right|}\right)\right|^{0.5} \operatorname{sgn}\left[\ln \left(\frac{S}{\left|R_{1}\right|}\right)\right]
$$

where $S$ is the signal power and $R_{1}$ is the covariance at lag 1 .
Melnikov and Zrnić (2004) found that this 0,1-lag autocovariance estimator does better than other estimators for the large spectral widths in which we are interested here. They suggest the maximum spectrum width must be less than about $0.6 v_{N}$, where $v_{N}$ is the Nyquist velocity. This maximum width can also be expressed by $\left(v_{N} / \pi\right) \ln \left(M^{0.5}\right)$, where $M$ is the number of samples. For the HIWRAP observations presented in this paper, $v_{N}$ is $\sim 24 \mathrm{~m} \mathrm{~s}^{-1}$ for $\mathrm{Ku}$ band and $10 \mathrm{~m} \mathrm{~s}^{-1}$ for Ka band, assuming a maximum PRF of $4516 \mathrm{~Hz}$ and 64 samples. This implies that the spectral width estimator is valid for $\sigma_{v}<15.9 \mathrm{~m} \mathrm{~s}^{-1}$ for Ku band and $\sigma_{v}<6.6 \mathrm{~m} \mathrm{~s}^{-1}$ for Ka band. In the more turbulent updraft regions of the flight lines presented in this paper, spectral width estimates from Eq. (A1) peaked at $\sim 10 \mathrm{~m} \mathrm{~s}^{-1}$ in the $\mathrm{Ku}$ band data. The Ka-band spectrum widths were unrealistically low in the updraft region, suggesting that the Eq. (A1) assumptions were failing (figure not shown). In general, we would expect lower values at $\mathrm{Ka}$ band because of the narrower beamwidth of the HIWRAP Ka-band antenna as compared with $\mathrm{Ku}$ band. Our conclusion from the above is that the Ku-band velocities are valid in the convective updrafts since adjacent pulses are correlated based on spectral width estimates from the data, and the spectral widths are less than $0.4 v_{N}$ even in the updraft regions. The large spectral widths combined with low signal-to-noise ratio in highly attenuated updraft regions are likely the cause of poor or missing velocity estimates at Ka band, however; this is the case in Figs. 9f and 12f. The variance of the Doppler velocity can be estimated through perturbation analysis. For large signal-to-noise ratios and a narrow $\sigma_{v}=10 \mathrm{~m} \mathrm{~s}^{-1}, \operatorname{var}(\hat{v})-\sigma_{v} \lambda /\left(8 M T_{s} \pi^{1 / 2}\right)$ [Doviak and Zrnić 1993, their Eq. (6.23)] provides an uncertainty of $\sim 1 \mathrm{~m}^{2} \mathrm{~s}^{-2}$ for Ku-band Doppler velocity. We have not provided corresponding Ka-band error estimates in these worst-case situations since the autocovariance estimators do not perform well at this frequency.

\section{REFERENCES}

Aydin, K., T. A. Seliga, and V. Balaji, 1986: Remote sensing of hail with a dual linear polarization radar. J. Climate Appl. Meteor., 25, 1475-1484.

Battaglia, A., M. O. Ajewole, and C. Simmer, 2006: Evaluation of radar multiple-scattering effects from a GPM perspective. Part II: Model results. J. Appl. Meteor. Climatol., 45, 16481664.

—, S. Tanelli, S. Kobayashi, D. Zrnic, R. J. Hogan, and C. Simmer, 2010: Multiple-scattering in radar systems: A review. J. Quant. Spectrosc. Radiat. Transfer, 111, 917-947.

_- T. Augustynek, S. Tanelli, and P. Kollias, 2011: Multiple scattering identification in spaceborne W-band radar measurements of deep convective cores. J. Geophys. Res., 116, D19201, doi:10.1029/2011JD016142. 
Beard, K. V., 1985: Simple altitude adjustments to raindrop velocities for Doppler radar analysis. J. Atmos. Oceanic Technol., 2, 468-471.

Bluestein, H. B., E. W. McCaul Jr., G. P. Byrd, G. R. Woodall, G. Martin, and S. Keighton, 1988: Mobile sounding observations of a thunderstorm near the dryline: The Gruver, Texas storm complex of 25 May 1987. Mon. Wea. Rev., 116, 1790-1804.

Braun, S., and Coauthors, 2013: NASA's Genesis and Rapid Intensification Processes (GRIP) field experiment. Bull. Amer. Meteor. Soc., 94, 345-363.

Bringi, V. N., J. Vivekanandan, and J. D. Tuttle, 1986: Multiparameter radar measurements in Colorado convective storms. Part II: Hail detection studies. J. Atmos. Sci., 43, 2564-2577.

Doviak, R. J., and D. S. Zrnić, 1993: Doppler Radar and Weather Observations. 2nd ed. Academic Press, $562 \mathrm{pp}$.

Durden, S. L., L. Li, E. Im, and S. H. Yueh, 2003: A surface reference technique for airborne Doppler radar measurements in hurricanes. J. Atmos. Oceanic Technol., 20, 269-275.

Grecu, M., L. Tian, W. S. Olson, and S. Tanelli, 2011: A robust dual-frequency radar profiling algorithm. J. Appl. Meteor. Climatol., 50, 1543-1557.

Heymsfield, G. M., B. Geerts, and L. Tian, 2000: TRMM precipitation radar reflectivity profiles as compared with highresolution airborne and ground-based radar measurements. J. Appl. Meteor., 39, 2080-2102.

- , L. Tian, A. J. Heymsfield, L. Li, and S. Guimond, 2010: Characteristics of deep and subtropical convection from nadirviewing high-altitude airborne radar. J. Atmos. Sci., 67, 285-308.

Horie, H., Y. Ohno, and N. Takahashi, 2010: The external calibration study for EarthCARE/CPR. Proc. Geoscience and Remote Sensing Symp., Honolulu, HI, IEEE, 1895-1898.

Hou, A. Y., G. Skofronick-Jackson, C. Kummerow, and J. M. Shepherd, 2008: Global precipitation measurement. Precipitation: Advances in Measurement, Estimation and Prediction, S. Michaelides, Ed., Springer-Verlag, 131-169.

Knight, N. C., and A. J. Heymsfield, 1983: Measurement and interpretation of hailstone density and terminal velocity. J. Atmos. Sci., 40, 1510-1516.

Kumjian, M. R., and A. V. Ryzhkov, 2008: Polarimetric signatures in supercell thunderstorms. J. Appl. Meteor. Climatol., 47, 1940-1961.

_, S. Ganson, and A. Ryzhkov, 2012: Freezing of raindrops in deep convective updrafts: A microphysical and polarimetric model. J. Atmos. Sci., 69, 3471-3490.

Kummerow, C., and Coauthors, 2000: The status of the Tropical Rainfall Measuring Mission (TRMM) after two years in orbit. J. Appl. Meteor., 39, 1965-1982.

Le, M., and V. Chandrasekar, 2012: Precipitation type classification method for dual frequency precipitation radar (DPR) on board the GPM. IEEE Trans. Geosci. Remote Sens., 51, 1784-1790.

Li, L., G. Heymsfield, J. Carswell, D. Schaubert, M. Mclinden, M. Vega, and M. Perrine, 2011: Development of the NASA High-Altitude Imaging Wind and Rain Airborne Profiler (HIWRAP) for tropical storm research. Preprints, Aerospace Conf., Big Sky, MT, IEEE, 8 pp.

Liao, L., and R. Meneghini, 2011: A study on the feasibility of dualwavelength radar for identification of hydrometeor phases. J. Appl. Meteor. Climatol., 50, 449-456.

McLinden, M., J. Carswell, L. Li, G. Heymsfield, A. Emory, J. Cervantes, and L. Tian, 2013: Utilizing versatile transmission waveforms to mitigate pulse-compression range sidelobes with the HIWRAP radar. IEEE Geosci. Remote Sens. Lett., doi:10.1109/LGRS.2013.2241729, in press.
Melnikov, V. M., and D. S. Zrnić, 2004: Estimates of large spectrum width from autocovariances. J. Atmos. Oceanic Technol., 21, 969-974.

Meneghini, R., and T. Kozu, 1990: Spaceborne Weather Radar. Artech House, 199 pp.

Mitrescu, C., S. Miller, J. Hawkins, T. L'Ecuyer, J. Turk, P. Partain, and G. Stephens, 2008: Near-real-time applications of CloudSat data. J. Appl. Meteor. Climatol., 47, 1982-1994.

Musil, D. J., S. A. Christopher, R. A. Deola, and P. L. Smith, 1991: Some interior observations of southeastern Montana hailstorms. J. Appl. Meteor., 30, 1596-1612.

Nelson, S. P., 1983: The influence of storm flow structure on hail growth. J. Atmos. Sci., 40, 1965-1983.

Payne, C. D., T. J. Schuur, D. R. MacGorman, M. I. Biggerstaff, K. M. Kuhlman, and W. D. Rust, 2010: Polarimetric and electrical characteristics of a lightning ring in a supercell storm. Mon. Wea. Rev., 138, 2405-2425.

Picca, J. C., and A. V. Ryzhkov, 2012: A dual-wavelength polarimetric analysis of the 16 May 2010 Oklahoma City extreme hailstorm. Mon. Wea. Rev., 140,1385-1403.

—, M. Kumjian, and A. Ryzhkov, 2010: $Z_{\mathrm{DR}}$ columns as a predictive tool for hail growth and storm evolution. Preprints, 25th Conf. on Severe Local Storms, Denver, CO, Amer. Meteor. Soc., 11.3. [Available online at https://ams.confex.com/ ams/pdfpapers/175750.pdf.]

Sadowy, G. A., A. C. Berkun, W. Chun, E. Im, and S. L. Durden, 2003: Development of an advanced airborne precipitation radar. Microwave J., 46, 84-98.

Sauvageot, H., 1992: Radar Meteorology. Artech House, $366 \mathrm{pp}$.

Stephens, G. L., and Coauthors, 2008: CloudSat mission: Performance and early science after the first year of operation. J. Geophys. Res., 113, D00A18, doi:10.1029/2008JD009982.

Tanelli, S., E. Im, S. L. Durden, L. Facheris, and D. Giuli, 2002: The effects of nonuniform beam filling on vertical rainfall velocity measurements with a spaceborne Doppler radar. J. Atmos. Oceanic Technol., 19, 1019-1034.

_ S. L. Durden, and E. Im, 2006: Simultaneous measurements of $\mathrm{Ku}$ - and Ka-band sea surface cross sections by an airborne radar. IEEE Geosci. Remote Sens. Lett., 3, 359-363. , and Coauthors, 2011: NASA's integrated Instrument Simulator Suite for Atmospheric Remote Sensing from spaceborne platforms (ISSARS) and its role for the ACE and GPM missions. Proc. Earth Science Technology Forum, Pasadena, CA NASA. [Available online at http://esto.nasa.gov/conferences/ estf2011/papers/Tanelli_ESTF2011.pdf.]

Tian, L., G. M. Heymsfield, and R. C. Srivastava, 2002: Measurements of attenuation with airborne and ground-based radar in convective storm over land and its microphysical implications. J. Appl. Meteor., 41, 716-733.

Ulbrich, C. W., 1977: Doppler radar relationships for hail at vertical incidence. J. Appl. Meteor., 16, 1349-1359.

Wakimoto, R. M., and V. N. Bringi, 1988: Dual-polarization observations of microbursts associated with intense convection: The 20 July storm during the MIST project. Mon. Wea. Rev., 116, 1521-1539.

Weisman, M. L., and J. B. Klemp, 1982: The dependence of numerically simulated convective storms on vertical wind shear and buoyancy. Mon. Wea. Rev., 110, 504-520.

Zipser, E. J., D. J. Cecil, C. Liu, S. W. Nesbitt, and D. P. Yorty, 2006: Where are the most intense thunderstorms on Earth? Bull. Amer. Meteor. Soc., 87, 1057-1071. 